\title{
WestVirginiaUniversity
}

THE RESEARCH REPOSITORY @ WVU

Graduate Theses, Dissertations, and Problem Reports

2012

\section{Adolescent Autonomy Development and Problematic Eating Patterns}

Kaitlyn A. Ferris

West Virginia University

Follow this and additional works at: https://researchrepository.wvu.edu/etd

\section{Recommended Citation}

Ferris, Kaitlyn A., "Adolescent Autonomy Development and Problematic Eating Patterns" (2012). Graduate Theses, Dissertations, and Problem Reports. 4852.

https://researchrepository.wvu.edu/etd/4852

This Thesis is protected by copyright and/or related rights. It has been brought to you by the The Research Repository @ WVU with permission from the rights-holder(s). You are free to use this Thesis in any way that is permitted by the copyright and related rights legislation that applies to your use. For other uses you must obtain permission from the rights-holder(s) directly, unless additional rights are indicated by a Creative Commons license in the record and/ or on the work itself. This Thesis has been accepted for inclusion in WVU Graduate Theses, Dissertations, and Problem Reports collection by an authorized administrator of The Research Repository @ WVU. For more information, please contact researchrepository@mail.wvu.edu. 
Adolescent Autonomy Development and Problematic Eating Patterns

Kaitlyn A. Ferris, B.A.

Thesis submitted to the Eberly College of Arts and Sciences

at West Virginia University in partial fulfillment of the requirements

for the degree of

Master of Science

in

Psychology

Aaron Metzger, Ph.D. Chair

Julie Patrick, Ph.D.

Christina Duncan, Ph.D.

Department of Psychology

Morgantown, West Virginia

2012

Keywords: adolescence, autonomy, eating 


\section{Abstract \\ Adolescent Autonomy Development and Problematic Eating Patterns Kaitlyn A. Ferris}

Adolescence is a developmental time period associated with increased autonomy from parents and more independent decision-making. Adolescents strive to control areas of their life once solely controlled by parents, and food and eating decisions are two areas over which adolescents may want to have sole control. In addition, there may be heterogeneity in adolescents' beliefs about food-related behavior as well as adolescents' actual eating patterns. The current study examined parents' and adolescents' domain beliefs about food and whether adolescents' domain beliefs about such behaviors were associated with problematic eating patterns. Participants included 102 female caregiver-adolescent dyads with children between the ages of 12-17 years $(M=14.65)$ and female caregivers between the ages of 29 to 65 years $(M=$ 43.79). Female caregivers and adolescents completed self-report measures which assessed decision-making about various food-related behaviors, the harmfulness of different eating behaviors, and adolescents' engagement in problematic (under-/over-eating) eating patterns. Female caregivers viewed decisions about food-related issues as requiring more parental input than adolescents, while older teens viewed food-related issues as up to them to decide compared to younger teens. Female caregivers and adolescents, regardless of age, did not differ in their harmfulness judgments about food and eating behavior. Additionally, increased adolescent decision-making about food-related behavior was associated with increased over-eating behavior, while increased adolescent harmfulness ratings of food were associated with increased restrictive eating. 


\section{TABLE OF CONTENTS}

I. Introduction (pp. 1-13)

a. Social-Cognitive Theory and Adolescent Autonomy Development (pp. 1-3)

b. Social Domain Theory (pp. 3-4)

c. Multifaceted Issues in Parent-Adolescent Relationships (pp. 4-6)

d. Eating as a Multifaceted Issue (pp. 6-7)

e. Associations between Beliefs and Behavior (pp. 7-8)

f. Moderators Affecting the Association between Eating Beliefs and Behavior (pp. $8-10)$

g. Measuring Problem Eating Behavior on a Continuum (pp. 10-11)

h. Control Variables (pp. 11)

i. Statement of Problem (pp. 11-13)

II. Research Questions and Hypotheses (pp. 13-17)

a. Research Question 1 (pp. 13-14)

b. Research Questions 2 (pp. 14)

c. Research Question 2a (pp. 14-15)

d. Research Question 3 (pp. 15-16)

e. Exploratory Research Question 4 (pp. 16-17)

III. Method (pp. 18-22)
a. Participants (pp. 18-19)
b. Procedure (pp. 19-20)
c. Measures (pp. 20-22)

IV. Results (pp. 22-27) 
a. Data Cleaning and Preliminary Analyses (pp. 22-23)

b. Female Caregivers' and Adolescents' Domain Beliefs about Food/Eating Behavior (pp. 23-24)

c. Adolescents' Domain Beliefs about Food/Eating Behavior and their Actual Eating Patterns (pp. 24-25)

d. The Discrepancy between Female Caregivers' and Adolescents' Domain Beliefs about Food/Eating Behavior and Adolescent Problematic Eating Patterns (pp. 2527)

V. Discussion (pp. 27-40)

a. Limitations (pp. 35-37)

b. Implications and Future Directions (pp. 37-40)

VI. References (pp. 41-48)

VII. Table 1: Adolescent Demographic Descriptive Statistics (pp. 49)

VIII. Table 2: Female Caregiver Demographic Descriptive Statistics (pp. 50)

IX. Table 3: Correlations for Key Variables (pp. 51)

X. Table 4: Means and Standard Errors for Female Caregivers' and Adolescents' Ratings of the Harmfulness of Food/Eating Behaviors (pp. 52)

XI. Table 5: Means and Standard Errors for Female Caregivers' and Adolescents' Ratings of Decision-Making about Food/Eating Behavior (pp. 53)

XII. Table 6: Regression Table for the Association between Adolescents' Domain Beliefs about Food/Eating Behavior and Over-Eating Behavior (pp. 54)

XIII. Table 7: Regression Table for the Association between Adolescents' Domain Beliefs and Food/Eating Behavior and Under-Eating Behavior (pp. 55) 
XIV. Table 8: Regression Table for the Association between the Discrepancy of Female Caregivers' and Adolescents' Domain Judgments about Food/Eating Behavior and Over-Eating Behavior (pp. 56)

XV. Table 9: Regression Table for the Association between the Discrepancy of Female Caregivers' and Adolescents' Domain Judgments about Food/Eating Behavior and Under-Eating Behavior (pp. 57)

XVI. Figure 1: Discrepancy between Female Caregivers' and Adolescents' Decisionmaking Beliefs by Adolescent Age Interaction Graph (pp. 58)

XVII. Figure 2: Discrepancy between Female Caregivers' and Adolescents' Harmfulness Judgments by Adolescent Body Image Dissatisfaction Level Interaction Graph (pp. 59)

XVIII. Figure 3: Differences in Female Caregivers' and Adolescents' Decision-making Beliefs Moderated by Adolescent Age (pp. 60)

XIX. Appendices (pp. 61-72) 
Adolescence is a time period associated with changes in the parent-adolescent relationship, and conflict often arises within such relationships as adolescents claim personal jurisdiction over new areas of their life. Food and eating-related behavior are two potential areas adolescents may seek to control. As a result, the teenage years are an ideal developmental time period in which to study domain beliefs about these issues because adolescents have greater freedom to make decisions about what types of food they eat, when they eat, and how much they eat. Eating is important to investigate because the developmental trajectory of eating may differ for adolescents from non-clinical, community-dwelling samples compared to those meeting established criteria for clinical diagnosis. In addition, independent decision-making, specifically healthy choices, about food are critical for successful aging in adulthood.

Social domain theory is a social-cognitive framework which allows for the study of both age-related changes in social reasoning and inter-individual variation in adolescent beliefs and behavior. Previous research (Nucci, 1981; Smetana \& Asquith, 1994; Smetana, 1995; Smetana, 1995a; Smetana, 2002) has used this framework to investigate the developmental trajectory of adolescent personal jurisdiction beliefs regarding such issues as curfew times and friendship choices. Additionally, research from this theoretical perspective has been used to explore associations between adolescent beliefs and behavior over such issues as drug use and civic responsibility. The current study applies social domain theory to an examination of age-related differences in adolescents' domain beliefs about eating, and the association between adolescents' attitudes toward eating and their engagement in problematic eating behaviors.

\section{Social-Cognitive Theory and Adolescent Autonomy Development}

During childhood, parents are seen as unquestioned authority figures and parent-child relationships are hierarchical with parents in control of many areas of the child's life (Steinberg 
\& Morris, 2001). Parents are the sole decision makers about what clothes the young child wears, what friends the child socializes with, and what foods the child eats at mealtime. In contrast, adolescence is a time of increased autonomy from parents and identity exploration. Contrary to older theoretical models (Freud, 1946; Freud, 1953; Hall, 1916), newer research has found that adolescent autonomy development does not involve full-fledged rebellion or detachment from parents (Arnett, 1999; Smetana, Campione-Barr, \& Metzger, 2006). Rather, most adolescents experience gradually increasing emotional and behavioral autonomy in the context of warm and caring parent-adolescent relationships. However, this developmental time period is also characterized by frequent low-intensity conflict with parents (Smetana, Campione-Barr, \& Metzger, 2006; Steinberg \& Morris, 2001).

According to one theoretical vantage, parent-adolescent conflict about various issues occurs because adolescents want more control over areas of their life (Nucci, 1981; Smetana \& Asquith, 1994; Smetana, 1995; Smetana, 1995a; Smetana, 2002). From this perspective, adolescents actively contribute to their own autonomy development by claiming control over areas of their life once solely controlled by parents. Conflict often arises within parent-adolescent relationships when adolescents and parents disagree about the issues over which adolescents should have sole control and those which parents should control. Larger discrepancies between parents' and adolescents' beliefs concerning an issue may also contribute to problematic outcomes. Through this conflict, parents and adolescents renegotiate the boundaries of their relationship as adolescents gradually gain more autonomy by claiming a wider array of issues and behaviors as up to them to decide (Smetana, 1995, 1995a). Parent-adolescent relationships gradually become more egalitarian as parents give their teenager expanded freedoms and privileges in order to allow adolescents to form their own, unique identities (Arnett, 2001; 
Arnett, \& Taber, 1994; Chen, Lay, \& Wu, 2005; Schwartz \& Pantin, 2006; Smetana, 2002;

Steinberg \& Morris, 2001). Overall, adolescents gain increased autonomy, greater ability to make decisions about areas in their life, and more equality within the parent-adolescent relationship during this developmental time period.

Social domain theory. During adolescence, parents and teenagers may interpret issues from different domains of social knowledge and different interpretations often lead to parentadolescent conflict as parents and adolescents renegotiate the boundaries of parental authority (Smetana, Campione-Barr, \& Metzger, 2006; Steinberg \& Morris, 2001). Different interpretations result because the social world is complex, and parents and adolescents may concentrate on different aspects of social situations (Smetana, 2002). Domain beliefs have been used to examine many different topics on which parents and adolescents disagree, such as adolescent curfew times, dating patterns, and drug and alcohol use; however, very little research has investigated parents' and adolescents' domain beliefs about eating behaviors, such as whether or not to eat junk food, snack between meals, or continue to eat when already full (Smetana, 1989; Nucci, 1981, Smetana \& Asquith, 1994; Smetana, 2002; Smetana, CampioneBarr, \& Daddis, 2004; Turiel, 1989). Decisions about these issues arise during adolescence because teenagers have increased freedom from parents and spend more time outside the home with peers (Larson et al., 1996). An investigation of parents' and adolescents' conceptualizations of eating behaviors would provide new insights into adolescents' developing social cognitions. Turiel (1989) originally identified three domains of social knowledge; moral, conventional, and psychological. Subsequent research has further divided the psychological domain, distinguishing personal from prudential issues (Smetana, 1992). Moral behavior is obligatory and generalizable across situations and social contexts, and moral judgments are 
based on concepts of justice, welfare, and fairness (Semtana, 1992). Moral rules are not contingent on societal rules or standards, and research has found that even young children can identify aspects of moral acts, and typically justify morally wrong acts by appealing to fairness, obligations or another person's welfare (Smetana, 1989a). Social conventions entail rules that coordinate interactions between people in specific social systems. In contrast to moral acts, conventions are dependent on rules and authority, exist in a particular societal or cultural context, and are not generalizable across contexts. Example moral and conventional issues include hitting a sibling and eating at the dinner table without utensils, respectably.

Prudential acts involve issues of self-harm or threats to individual safety. Whereas moral rules pertain to acts that harm others, prudential rules govern actions that have physical and/or harmful consequences to the decision maker (Smetana, 1992), and research has found that even young children are able to distinguish prudential and moral acts in their judgments and justifications (Tisak \& Turiel, 1984). Example prudential acts utilized in previous research on children and adolescents include riding a skateboard or bicycle without a helmet, failing to wear a jacket in the winter time or touching a hot stove. Finally, the personal domain involves issues that children, adolescents, and parents view as beyond the realm of social regulation and moral concern (Nucci, 1981; Smetana, 1988; Smetana, 1989; Smetana, 1993; Smetana \& Asquith, 1994; Smetana, 1995; Smetana \& Bitz, 1996). Prototypical personal issues include what individuals wear, how individuals should spend their own money, and what individuals write in their diaries or say to friends on the phone.

Multifaceted issues in parent-adolescent relationships. Multifaceted issues are unique in that different individuals could potentially apply judgments from multiple domains and may contain personal, conventional and prudential components (Smetana, 1995; Turiel, Hildebrandt, 
Wainryb, 1991). Individual differences in reasoning about multifaceted issues stem from differing levels of social understanding, experiences, and vantages on the issue. Examples of typical multifaceted issues from parent-adolescent research include the cleanliness of the teen's bedroom, ability to date/have romantic relationships, and ability to choose peer group/friends. Parents and adolescents agree that parents have the right to regulate moral and most conventional issues. They also agree that adolescents should have control over some personal issues in early adolescence or even childhood (Nucci, 1981; Nucci \& Smetana, 1996; Smetana \& Asquith, 1994; Smetana, 1995; Smetana, 2002). However, conflict arises over multifaceted issues as parents and adolescents interpret the same issue from different domains of reasoning. Parents may focus on control and authority, setting rules or keeping their child safe when reasoning about issues, while adolescents may focus on personal rights and making decisions on their own. For example, adolescents may view an issue such as their curfew as personal ("It should be up to me to decide how late I stay out"), focusing on personal prerogative, choice, and the fact that the outcomes of those decisions only affect the adolescent. In contrast, parents may focus on household rules, the household order, or parental authority ("This family has rules about how late children can stay out and everyone has to follow them"). Likewise, parents may concentrate on prudential (safety issues, potential self-harm for the teen) aspects of curfew violations ("Kids who stay out late potentially put themselves in dangerous situations and could get hurt": Smetana, 1995). Previous research on parent and adolescent domain-specific reasoning has located differences in the types of judgments parents and adolescents apply to prototypical multifaceted issues (Nucci, Guerra, \& Lee, 1991; Smetana \& Asquith, 1994). Compared to teens, parents tend to view such issues as entailing more self-harm (prudential reasoning) and more parental jurisdiction (conventional reasoning). 
Findings from several studies (Smetana, 1988; Smetana, 1989; Smetana, 1993, Smetana \& Asquith, 1994) suggest that multifaceted issues are central to explaining the shift from parentunilateral decision-making to parent-adolescent mutual decision-making. Adolescents drive their autonomy development and influence the transition from hierarchical parent-child relationships to egalitarian parent-adolescent relationships by laying claim to areas of their lives once considered conventional and prudential as personal issues.

Eating as a multifaceted issue. Research has not examined how parents and adolescents reason about different types of eating behaviors such as snacking between meals, eating junk food and eating large quantities of food when already full. Nucci and Smetana (1996) found that conflicts over food choice begin earlier in development. During childhood, parents believe decisions about "favorite foods" fall under the personal domain. However, overall healthy eating habits encompass more than selecting your "favorite foods," and involve an understanding of healthy eating practices, such as an avoidance of under-/over-eating, choosing healthy foods, and exercise techniques to maintain a weight appropriate for one's age. Thus, eating behavior involves personal decisions, but may also potentially entail family rules or health risk concerns. It is possible that adolescents view various types of eating behavior as personal and up to them to decide, while parents view the same behavior as conventional or prudential.

Parents' and adolescents' domain-specific judgments about eating-related issues might differ for several reasons. Adolescents may categorize eating as a personal issue because they believe they are mature enough to make individual decisions about what foods they consume and parents should not have a say in their decisions. Adolescents may also view eating as a less potentially harmful behavior than parents do, or view eating as a behavior that will only affect them, personally. Conversely, parents may feel that decisions about what their adolescent eats 
are up to them to decide because they are purchasing the food prepared for meals in the home and they are in-charge of the household. Parents may also categorize eating as a prudential issue because they are concerned about their teenager's health and nutrition, reasoning that adolescents may harm their bodies through unhealthy eating behaviors. Parents may not believe adolescents have the ability or nutrition knowledge to make the right decisions about what to eat, and that it is their job as primary caregivers to help keep their teenager at a healthy, age-appropriate weight.

\section{Associations between Beliefs and Behavior}

Social cognitive researchers have been interested in differences in developmental changes in adolescents' domain beliefs, and how such changes within the context of parent-adolescent relationships influence adolescent autonomy development. However, researchers are also interested in associations between adolescents' domain-related reasoning and their actual behavior, and previous research has located domain beliefs and behavior associations in areas such as abortion, drug use, and civic involvement (Smetana, 1981; Nucci, Guerra, \& Lee, 1991; Metzger \& Smetana, 2009). The following studies found inter-individual differences in domain beliefs about various multifaceted issues, and such belief differences were associated with individuals' behavior.

Smetana (1981) examined adolescents' and young adult women's domain judgments about abortion. Women who believed conception resulted in the creation of a person conceptualized abortion as a moral issue, and women who viewed abortion as a moral issue were more likely to carry the pregnancy full-term compared to women who conceptualized abortion as a non-moral issue. Similarly, Nucci, Guerra, and Lee (1991) found that adolescents varied in how they conceptualized using drugs and their domain-beliefs were associated with their actual drug use. Adolescents who were heavy drug users categorized smoking as a personal issue that 
was less wrong and less harmful compared to adolescents who were low-drug-users. Heavydrug-users were also more likely to view themselves as the sole authority figure when it came to making decisions about drug use. Finally, Metzger and Smetana (2009) examined adolescents' domain judgments about different community activities and their involvement in those activities. These researchers found adolescents' involvement in organized activities to be positively associated with their civic judgments regarding standard political involvement, community service behavior and social movement behavior.

Overall, these studies suggest that adolescents' domain beliefs about specific issues are related to their behavior in those areas, and that domain conceptualizations may help to explain inter-individual differences in various behaviors. No studies to date have examined the association between adolescents' domain specific judgments and problematic eating behaviors. Adolescents may vary in their conceptualization of eating activities, and these beliefs may be associated with individual differences in problematic eating patterns. Examining the association between adolescents' domain beliefs and their actual eating behavior may allow for an enhanced understanding of individual variation in the developmental trajectory of problematic eating patterns in a normative sample of adolescents.

Moderators affecting the association between eating beliefs and behavior. There are reasons to expect that the association between adolescents' domain beliefs about eating and their engagement in problematic eating behaviors may not be linear when examined longitudinally. A developmental goal for all adolescents is to eventually view eating as a personal issue; however, viewing snacking and eating junk food as personal choices may not be ideal for all adolescents. Specifically, adolescents' age, nutrition knowledge, and body image dissatisfaction may 
moderate the relationship between adolescents' domain beliefs about eating and under-/overeating behavior.

With age, adolescents tend to view more and more multifaceted issues from the personal domain, while parents tend to lag behind teens, continuing to conceptualize these same issues from the prudential or conventional domain (Smetana, Campione-Barr, \& Daddis, 2004; Smetana \& Daddis, 2002). However, Smetana and colleagues (Smetana, Campione-Barr, \& Daddis, 2004) found that viewing multifaceted issues as personal in early adolescence was associated with problematic outcomes for adolescents. Similarly, viewing eating behaviors as personal early in adolescence may be associated with under-/over-eating behavior, as young adolescents may lack the cognitive and decision-making skills necessary to properly regulate their diet.

Nutrition knowledge may moderate the association between eating beliefs and behavior. Healthy eating behaviors involve an understanding of dietary recommendations, food content, food choices and diet-disease relationships (Parmenter \& Wardle, 1999). Increased nutrition knowledge allows individuals to distinguish misconceptions from accurate knowledge about healthy eating behaviors. Adolescents who view decisions about eating as personal and who have a greater amount of nutrition knowledge may be able to evaluate the health risks associated with under-/over-eating, and as a result, they will engage in less problematic eating compared to adolescents who view decisions about eating as personal, but who have less nutrition knowledge.

Finally, the association between adolescents' domain beliefs and problematic eating behavior may vary as a function of adolescent body image dissatisfaction. Previous research (Jung \& Forbes, 2006; Saules et al., 2009; Wood \& Petrie, 2010) has found a positive association between body image dissatisfaction and engagement in disordered eating behaviors. Adolescents 
who view eating as a personal issue may be more likely to engage in under-/over-eating behaviors as a means to decrease their body image dissatisfaction if they are unhappy with their body shape compared to adolescents who view eating as a personal issue but are satisfied with their bodies.

\section{Measuring Problem Eating Behavior on a Continuum}

Previous research indicates that many adult health problems can be linked to unhealthy eating patterns established in childhood and adolescence (Dowdell \& Santucci, 2004), and that positive health behaviors tend to decrease during adolescence (Lohaus et al., 2009). Clinically diagnosed eating disorders represent one way to examine disordered eating patterns, and provide researchers with categorical distinctions between individuals meeting criteria for diagnosis and those who do not (APA, 2000). However, individuals can still display symptoms of problematic under-/over-eating behavior without meeting criteria for clinical diagnosis, and measuring problematic eating dichotomously may not be appropriate for normative samples (Peck \& Lightsey, 2008; Wood \& Petrie, 2010). Researchers have argued that subclinical versions of eating disorders are also important to investigate because negative health outcomes may result from less extreme problematic eating patterns (Franko \& Omori, 1999; Mintz \& Betz, 1988; Peck \& Lightsey, 2008; Shisslak et al., 1994; Wood \& Petrie, 2010). Overall, measuring problematic eating on a continuum provides researchers with a more complete picture of problematic eating behavior, including potential information concerning the developmental trajectory and antecedents of clinically diagnosed eating disorders during adolescence. Measuring eating along a continuum also allows researchers to examine both under- and overeating simultaneously, as variations in the type and severity of problematic eating may differ 
between individuals and may be differentially associated with adolescents' domain beliefs about food-related issues.

\section{Control Variables}

Previous research findings have indicated that socioeconomic status (SES) and gender both influence problematic eating patterns during adolescence. SES has been associated with both under- and over-eating behaviors (O'Dea \& Caputi, 2001), though other researchers have found few eating pathology differences across SES groups (O'Dea, 1994). The ratio of clinically-diagnosed eating disorders in adolescent populations is 3:1 in favor of females (Kjelsas et al., 2004); however, the prevalence of subclinical eating disorders is more equal for males and females (Walcott et al., 2003). Researchers have also observed differences between boys and girls in eating patterns, dieting activities and body image concerns with women more concerned about being overweight and men more focused on being too thin (Walcott et al., 2003). To establish a clearer association between adolescents' domain beliefs about eating and behavior, the analyses in the current study will control for the above factors.

\section{Statement of the Problem}

Adolescence is a time period associated with changes in the parent-adolescent relationship. Parents' and adolescents' differences in judgments about multifaceted issues provide an impetus for adolescent autonomy development (Smetana, 1988; Smetana, 1989; Smetana, 1993, Smetana \& Asquith, 1994). Food-related decisions may be one specific area of parent-adolescent disagreement, and investigating parents' and adolescents' beliefs about eating will provide additional insight into adolescent autonomy development and adolescent decisionmaking. Healthy eating behavior is a potential multifaceted issue because parents and adolescents may reason about it from different social domains. Previous research has not 
examined whether parents and adolescents conceptualize eating behaviors such as snacking, eating junk food, or under-/over-eating from different domains of social knowledge. Parents who are concerned with harming the body through unhealthy eating may be more likely to conceptualize eating as a prudential issue or believe it is their decision to make rules about eating for their family, conceptualizing eating as a conventional issue. In contrast, adolescents may be more likely to interpret such eating behaviors as personal, meaning that it is up to them to decide and involves little potential harm. Previous research (Smetana, 1992) suggests that parents and adolescents who judge issues to be under parental jurisdiction (parent decides with little or no input from the teen) are reasoning about these behaviors from the conventional domain. Individuals who attribute high levels of potential harm to these behaviors view them as prudential. In contrast, judging the issues to be less harmful and under adolescent jurisdiction is indicative of personal reasoning.

Investigating adolescent reasoning about food and healthy eating may also provide an alternative strategy for exploring ways in which cognitive processes influence the development of problematic eating patterns including under- and over-eating behaviors. No previous research has examined the association between adolescents' domain beliefs about eating and their actual eating behaviors. Findings from research utilizing social domain theory indicate that adolescents' judgments about complex, multifaceted issues, such as drug use and civic involvement, are associated with their behaviors (Metzger \& Smetana, 2009; Nucci, Guerra, \& Lee, 1991; Smetana, 1981). However, this previous research considered only linear associations between adolescent beliefs and behaviors. Less research has considered ways in which individual characteristics and inter-individual differences may impact the associations between domain conceptualizations and behavior. 
The first goal of the current study is to examine age-related differences in adolescents' domain beliefs about food-related issues. Parents' and adolescents' domain-specific judgments about different eating behaviors and whether these differences vary as a function of adolescent age will be examined. The second goal of the current study is to explore associations between adolescents' domain-related beliefs about eating behavior and their engagement in under-/overeating. Analytic models will examine whether these associations vary by adolescent age, nutrition knowledge, and body image dissatisfaction. While it is important for adults to be able to make independent decisions about eating behavior, for some adolescents, viewing eating as a purely personal issue may be associated with problematic eating patterns, particularly if the adolescent is too young, has low levels of nutrition knowledge, or has an unhealthy body image. A third exploratory aim is to investigate whether discrepancies in parents' and adolescents' domain beliefs about food are associated with problematic eating patterns for teenagers, and whether such associations vary as a function of adolescent age, nutrition knowledge, and body image dissatisfaction. The degree to which parents and adolescents disagree about who makes decisions about food-related behaviors may also be associated with adolescents' engagement in problematic under- or over-eating.

\section{Research Questions and Hypotheses}

\section{Research Question 1}

Are there age-related differences in adolescents' domain beliefs about food-related behavior?

Hypothesis 1. Adolescence is a developmental time period when teenagers strive for greater autonomy and decision-making ability, and adolescents may seek decision-making control over eating behaviors, such as what type of food to eat, when to eat throughout the day, 
and how much food to consume (Smetana, Campione-Barr, \& Daddis, 2004; Smetana \& Daddis, 2002). Therefore, it is hypothesized that:

a. Older teens will rate adolescent eating behaviors (e.g. eating junk food, snacking, eating too much, eating too little) as less harmful than will younger teens.

b. Older teens will rate adolescent eating behaviors (e.g. eating junk food, snacking, eating too much, eating too little) as requiring less parental input and decision-making (parent decides) than will younger teens.

\section{Research Question 2}

Do parents and adolescents reason differently about eating behaviors?

Hypothesis 2. Research has found that while adolescents tend to rate multifaceted issues, such as eating behaviors, as personal, parents concentrate on prudential (harm) or conventional (parental authority) aspects of multifaceted issues (Nucci, Guerra, \& Lee, 1991; Smetana \& Asquith, 1994). Therefore, it is hypothesized that:

a. Parents will rate adolescent eating behaviors (e.g., eating junk food, snacking, eating too much, eating too little) as more harmful than will adolescents.

b. Parents will rate adolescent eating behaviors (e.g., eating junk food, snacking, eating too much, eating too little) as requiring more parental input and decision-making (parent decides) than will adolescents.

\section{Research Question 2a}

Will parents' and adolescents' domain judgments about eating vary as a function of the adolescents' age?

Hypothesis 2a. The anticipated main effects from research question 2 will be qualified by a domain judgment $\mathrm{X}$ age interaction. Previous research (Smetana, Campione-Barr, \& 
Daddis, 2004) found parents to be more likely to view multifaceted issues as conventional (decision-making) throughout adolescence, while adolescents are more likely to view multifaceted issues as conventional in early adolescence, but not in later adolescence. Therefore it is hypothesized that:

a. The harm and authority judgments of parents of early and late adolescents will not significantly differ.

b. Compared to early adolescents, late adolescents will rate eating behaviors as less harmful and less subject to parental decision-making authority.

\section{Research Question 3}

Are adolescents' domain beliefs about food-related issues associated with problematic eating, and is the association between adolescents' domain beliefs about food-related behavior qualified by inter-individual differences in several potential moderators, such as adolescent age, nutrition knowledge, and body image dissatisfaction views?

Hypothesis 3a. The association between adolescents' domain beliefs (personal versus prudential versus conventional) and under-/over-eating behavior will vary as a function of adolescent age. Based on previous research, problematic eating behavior will result for individuals who believe decisions about eating are up to them to decide, but who are in early adolescence. Previous research has indicated that too much adolescent-unilateral decisionmaking (autonomy) in early adolescence is associated with poor adjustment in a number of areas in later adolescence (Smetana, Campione-Barr, \& Daddis, 2004). Therefore it is hypothesized that:

a. Lower harm and parental decision-making authority judgments about eating will be associated with problem eating behavior for early adolescents. 
b. Harm and parental decision-making authority judgments about eating will not be associated with problem eating behavior for late adolescents.

Hypothesis $3 \mathbf{b}$. The association between adolescent domain beliefs about eating and their problematic eating behaviors are hypothesized to vary as a function of adolescent nutrition knowledge. Problematic eating patterns will result when adolescents view eating as a personal choice and they are uneducated about healthy eating patterns. Therefore, it is hypothesized that:

a. Lower harm and parental decision-making authority judgments about eating will be associated with problem eating behavior when adolescents have low levels of nutrition knowledge.

b. Harm and parental decision-making authority judgments about eating will not be associated with problem eating behavior when adolescents have high levels of nutrition knowledge.

Hypothesis 3c. The association between adolescents' domain beliefs and problematic eating behaviors will vary as a function of adolescent body image dissatisfaction views. Problematic eating patterns will result when adolescents view eating as a personal issue and they are dissatisfied with their body image. Therefore it is hypothesized that:

a. Lower harm and parental decision-making authority judgments about eating will be associated with problem eating behavior when adolescents have low levels of body satisfaction.

b. Harm and parental decision-making authority judgments about eating will not be associated with problem eating behavior when adolescents have high levels of body satisfaction.

\section{Exploratory Research Question 4}


Is the discrepancy between parents' and adolescents' domain beliefs about food-related behavior associated with problematic eating patterns for adolescents, and do the associations between the discrepancy of parents' and adolescents' domain judgments about food-related behavior and adolescent eating patterns vary as a function of adolescent age, body image dissatisfaction, and nutrition knowledge?

Exploratory hypothesis 4. The discrepancy between parents' and adolescents' domain beliefs about food-related behavior and subsequent adolescent problematic eating patterns will vary as a function of adolescent age, body image dissatisfaction, and nutrition knowledge. Therefore it is hypothesized that:

a. Problematic eating patterns will result when there is a discrepancy in parents' and adolescents' domain beliefs about food and the adolescent is an early adolescent. Problematic eating patterns will not result when there is a discrepancy in parents' and adolescents' domain beliefs about food and the adolescent is a late adolescent.

b. Problematic eating patterns will result when there is a discrepancy in parents' and adolescents' domain beliefs about food and the adolescent has low levels of body image satisfaction. Problematic eating patterns will not result when there is a discrepancy in parents' and adolescents' domain beliefs about food and the adolescent has high levels of body image satisfaction.

c. Problematic eating patterns will result when there is a discrepancy in parents' and adolescents' domain beliefs about food and the adolescent has low levels of nutrition knowledge. Problematic eating patterns will not result when there is a discrepancy in parents' and adolescents' domain beliefs about food and the adolescent has high levels of nutrition knowledge. 


\section{Method}

\section{Participants}

One hundred and two parent-adolescent dyads were recruited from Morgantown, West Virginia and the surrounding area to take part in a study for monetary compensation. Adolescents were recruited from various organizations catering to adolescent youth (e.g. Boy's and Girl's Club, church youth groups, youth sports organizations). In addition, a local medical clinic and three area high-schools assisted with participant recruitment. The medical clinic mailed parent information letters and recruitment flyers to all parents of adolescents in the desired age range. Graduate students and undergraduate research assistants recruited participants in the classrooms and at athletic and community events at the local high schools. In order to participate in this study, adolescents needed to recruit at least one adult caregiver. All adults who serve as primary caregivers to the adolescent were eligible including biological parents, stepparents, legal guardians, aunts, uncles or grandparents with whom the adolescent lives fulltime. The current study included female primary caregivers. Female caregivers were examined in the current study because much previous social-cognitive/social domain literature has used mother-adolescent dyads (Nucci \& Smetana, 1996; Smetana 1993; Smetana, 2002; Smetana, Crean, \& Daddis, 2002; Smetana, Campione-Barr, \& Daddis, 2004; Smetana \& Daddis, 2002). Less research in this area has used fathers as a comparison group (Smetana, 1989; Smetana, 1988; Smetana, 1995a; Smetana \& Asquith, 1994).

Adolescents in this sample ranged in age from 12-17 years $(M=14.65, S D=1.57)$, and were primarily Caucasian/White (70.6\%) and female (62.7\%). The majority of adolescents reported receiving mostly A's or some A's and some B's in school (69.6\%). Female caregivers in the sample ranged in age from 29 to 65 years $(M=43.79, S D=7.14)$ and were primarily 
Caucasian/White (91.2\%). The majority of female caregivers in this sample identified themselves as the adolescent's birth mother (94.1\%) and as currently married (73.5\%). Two adoptive mothers, 1 parental guardian, 1 step-mother, 1 grandmother, and 1 aunt also served as primary female caregivers. More than half of female caregivers $(52 \%)$ reported being employed outside the home, and having a family income of greater than $\$ 25,000(87.2 \%)$. See tables 1 and 2 for a complete list of participant demographic characteristics, and Appendix A for demographic questions.

\section{Procedure}

Family visits took place primarily in participants' homes; however, they also took place at the research lab and in community-group locations (e.g. public library, church). Female caregivers gave informed consent for themselves and their adolescent before participating, while adolescents gave informed assent before participating. After giving informed consent and assent, all participants received payment for participating. Next, female caregivers and adolescents participated in a dyadic discussion task; they discussed several topics, such as civic engagement, food and eating habits, alcohol experimentation, and internet and cell phone use for seven minute time intervals. The conversations involved the female caregiver and adolescent taking turns reading cue cards out loud for each topic, and then discussing whatever came to mind. Several cue cards were developed for each topic, and they were used as talking points for the female caregiver and adolescent. After the dyadic interaction task, the female caregiver and adolescent completed survey questionnaires in separate rooms. The questionnaire asked female caregivers and adolescents to answer questions about their eating behaviors, nutrition knowledge, body image dissatisfaction, domain beliefs and decision-making control in reference to various 
activities, including eating, and demographic information. The order in which these questions were asked was fixed for all participants.

\section{Measures}

Figure rating scale - adolescent report. This scale is a widely used psychometric measure of individual's perceptions of his/her body image (Duncan et al., 2005; Platte et al., 2000; Stunkard, Sorensen, \& Schulsinger, 1983; Swami et al., 2011; Appendix B). Adolescents were presented with a series of nine body size pictures on a spectrum from thin to obese. Adolescents circled the image that is closest to their "real" body shape, and the image that is closest to their "ideal" body shape. This item is scored by subtracting the participants' ideal body image number from their real body image number. Positive values indicate that the participant wants to be thinner, while negative values indicate that the participant wants to be heavier. The current study used the absolute value of participants' scores as a measure of poor body image.

General nutrition knowledge questionnaire for adults - adolescent report. This scale examined adolescents' general knowledge about nutrition and healthy eating behaviors (Parmenter \& Wardle, 1999; Appendix C). The current study utilized specific items (37 items) from the full scale, which were appropriate for younger adolescents and focused on food content. Adolescents answered questions such as, "Do you think experts put pasta in the starchy food group?" Each correctly answered item received a score of 1 point. The highest possible score adolescents could obtain on this measure was a 37, and higher scores indicated greater nutrition knowledge (Cronbach's $\alpha=.69 ; 37$ items). Previous research which utilized adults found the scale to have good internal reliability $(\alpha=.97)$. The decreased reliability observed in the current study may have resulted because the full scale was not used; a complete understanding of nutrition knowledge encompasses more than information about food content. In addition, 
previous research utilizing this measure did not specify a percentile cut-off separating individuals with high levels of nutrition knowledge and those with low levels. However, one study (Parmenter \& Wardle, 2000) discussed the association between nutrition knowledge and consumption of dietary recommendations for fruits, vegetables and fats; individuals in the top quintile of nutrition knowledge reported consumption of more fruits and vegetables and less fat.

Problematic eating behaviors - adolescent report. The Dutch Eating Behavior Scale (van Strien et al., 1986; Appendix D) was used to examine restrained, external and emotional eating behaviors. Adolescent responses were measured on a 5 -point Likert scale $(1=$ Never, $5=$ Very Often). Higher scores on each subscale (restrained, external and emotional eating) indicated more problematic eating in each of those areas. Participants' scores on the external and emotional subscales were averaged to assess over-eating behavior, while scores on the restrained subscale assessed under-eating behavior. These subscales were the primary measure used to assess adolescent problematic eating behaviors. (Cronbach's $\alpha$ : Restrained Eating Subscale $($ Under-eating $)=.90 ; 10$ items; Over-eating $($ External and Emotional Eating $)=.91,23$ items $)$.

\section{Domain Judgments}

\section{Parental restrictive control questionnaire (Smetana, 1988; Smetana \& Asquith,} 1994) - parent and adolescent report. Parents and adolescents answered questions about who in their family makes most of the decisions about different eating behaviors ("Who makes decisions about if $\mathrm{I} /$ teens eat junk food"). Responses were made on a 5-point Likert scale ( $1=$ Child decides alone, 2 = Child decides after discussing with his/her parents, $3=$ Parents and children decide together, 4 = Parent decides after discussing with the child, $5=$ Parent decides alone) (Smetana, 1995; Smetana, Crean, \& Daddis, 2002; Appendix E). Higher scores on this scale indicate a greater degree of parent input into family decision-making, while lower scores 
indicate more teen independent decision-making. (Cronbach's $\alpha$ : Parents $=.83,4$ items; Adolescents $=.83,7$ items) .

Harmfulness scale - parent and adolescent report. Additional eating-related items were added to a measure used by Nucci and colleagues (1991) to assess parents' and adolescents' beliefs about the harmfulness of different activities (Appendix F). This questionnaire was scored on a 5-point Likert scale $(1=$ Not harmful at all, $5=$ Extremely harmful). Parents and adolescents answered 4 questions about the harmfulness of different eating behaviors such as "How harmful is it if teens eat snacks between meals?" The parent and adolescent subscales had poor reliability (Cronbach's $\alpha$ : Parents $=.58,4$ items; Adolescents $=$ $.46,4$ items).

\section{Results}

\section{Data Cleaning and Preliminary Analyses}

Data were analyzed for missing values, outliers and normal distribution properties of all continuous variables. Tables 1-3 present the means, standard deviations, and correlations for female caregivers' and adolescents' demographic information, domain beliefs about food, and adolescents' engagement in under-/over-eating. There was a small amount of missing data; however, items missing from the study's key variables, specifically items on the DEBQ, and parental restrictive control scale (female caregivers' and adolescents' decision-making and harmfulness domain judgments) were imputed using scale-mean imputation. Missing data on demographic variables was not imputed for both female caregivers and adolescents (Adolescents $<7 \%$; Female caregivers $<8 \%$ ). Adolescents had difficulty completing one item on the nutrition knowledge survey, "How many servings of fruits and vegetables a day do you think experts are advising people to eat? (One serving could be, for example, an apple or a handful of chopped 
carrots)." This item was dropped from the scale because participants may not have understood what information the question was asking for. Two adolescents used ranges (as rated on a 9-point Likert scale 1 = image representing a very thin individual, $9=$ an image representing a very obese individual) to indicate how they currently looked and how they wished they looked on the body image dissatisfaction items. The average of the reported range was taken for these two participants to avoid missing data. The over-eating outcome variable was created from the average scores (standardized z-scores) on the external and emotional eating subscales of the DEBQ (van Strien et al., 1986). Finally, the original four items used to assess female caregivers' and adolescents' harmfulness ratings of food had poor reliability (Female caregivers: $\alpha=.58$; Adolescents: $\alpha=.46$ ). Three of the items assessed overeating, such as snacking between meals, continuing to eat when already full, and eating junk food, while one item assessed harmfulness ratings of dieting as a means to lose weight. Removing the item which assessed dieting not only improved the statistical fit of the variable, but it also provided a better conceptual breakdown of harmfulness ratings of over-eating from such ratings of under-eating behaviors. The revised subscales had improved reliability for adolescents $(\alpha=.59)$ and similar, poor reliability for female caregivers $(\alpha=.54)$. Although the reliability of the female caregivers' harmfulness judgments subscale was initially higher, the item assessing dieting was dropped to keep the scales consistent for female caregivers and adolescents.

\section{Female Caregivers' and Adolescents’ Domain Beliefs about Food/Eating Behavior}

Two factorial ANOVA's were used to examine whether female caregivers and adolescents differed in their domain judgments of eating-related behaviors (harmfulness and decision-making judgments), and whether such differences were moderated by adolescent age (Table 4). The first ANOVA was a 2 (parent vs. teen) X 2 (early vs. late adolescents) ANOVA 
run on the food-related items from the harmfulness subscale. Results indicated no significant main effects of age, $F(1,200)=2.75, p=.10, \eta_{\mathrm{p}}^{2}=.01$ or rater (e.g. parent versus teen), $F(1$, $200)=.63, p=.43, \eta_{\mathrm{p}}{ }^{2}=.003$. There was no significant difference between female caregivers' and adolescents', or older and younger adolescents' harmfulness ratings of food. No significant rater by age interaction emerged, $F(1,200)=.74, p=.39, \eta_{\mathrm{p}}{ }^{2}=.004$.

A similar 2 (parent/teen) X 2 (early/late adolescence) ANOVA was run on the foodrelated items from the decision-making subscale (Table 5). Results showed a significant main effect of rater, $F(1,200)=24.92, p<.001, \eta_{\mathrm{p}}{ }^{2}=.11$, indicating that female caregivers reported making significantly more decisions about food/eating behavior $(M=2.58, S E=.07)$ compared to their adolescent $(M=2.09, S E=.07)$. A significant main effect of age also resulted, $F(1,200)$ $=31.80, p<.001, \eta_{\mathrm{p}}{ }^{2}=.14$, indicating that older adolescents reported making more decisions about food/eating behavior $(M=2.06, S E=.07)$ compared to younger adolescents $(M=2.61, S E$ $=.07)$. There was no significant rater by age interaction, $F(1,200)=2.10, p=.15, \eta_{\mathrm{p}}{ }^{2}=.01$.

\section{Adolescents' Domain Beliefs about Food/Eating Behavior and their Actual Eating Patterns}

Two hierarchical regression analyses examined associations between adolescents' foodrelated domain judgments and their eating behavior. Adolescent problematic eating behaviors (under- and over-eating) as measured by scores on the DEBQ (van Strien et al., 1986) served as the dependent variables. In the first step, adolescent problematic eating behaviors were regressed on to participant gender and female caregivers' education. Adolescents' body image dissatisfaction, nutrition knowledge scores, and age were entered in the second step of the model. Adolescents' domain judgments, either harmfulness or decision-making (who decides), were entered into step three of the model. In the final step of the model, interactions between adolescent domain judgments and adolescent body image dissatisfaction, nutrition knowledge 
scores, and age were entered. To create the interaction terms for the hierarchical multiple regression analyses, the predictor variables (adolescents' harmfulness ratings and decisionmaking judgments) and moderator variables (age, BID, nutrition knowledge) were centered by subtracting the sample mean to create a new mean of zero. Interaction terms were created by multiplying the centered predictor variables with each of the centered moderator variables (Frazier et al., 2004).

In the first model, the association between adolescents' domain judgments and overeating behaviors (DEBQ - Emotional and External Eating Subscales) were examined. A significant main effect of adolescent decision-making resulted, indicating that decreased parental decision-making/input about food-related behavior was associated with increased adolescent over-eating $(\beta=-.25, p=.02)$. There was no significant main effect of adolescents' harmfulness ratings of food-related behavior. No significant interactions resulted (Table 6).

In the second model, the association between adolescents' domain judgments and undereating behaviors (DEBQ - Restrained Eating Subscale) were examined. A significant main effect of adolescents' body image dissatisfaction score resulted $(\beta=.29, p=.001)$, indicating that increased dissatisfaction with one's body image was associated with increased under-eating behaviors. A significant main effect of adolescents' harmfulness ratings of food-related behavior indicated that increased harmfulness ratings about food were associated with increased undereating behaviors $(\beta=.23, p=.02)$. There was no significant main effect of adolescents' decisionmaking about food. No significant interactions resulted (Table 7).

The Discrepancy between Female Caregivers' and Adolescents' Domain Beliefs about Food/Eating Behavior and Adolescent Problematic Eating Patterns 
Two hierarchical regression analyses were used to examine associations between the discrepancy of female caregivers' and adolescents' domain beliefs about food and adolescents' eating behavior. Adolescent problematic eating behaviors (under- and overeating) as measured by scores on the DEBQ (van Strien et al., 1986) served as the dependent variables. In the first step, adolescent problematic eating behaviors were regressed on to participant gender and female caregivers' education. Adolescents' body image dissatisfaction, nutrition knowledge scores, and age were entered in the second step of the model. The discrepancy between female caregivers' and adolescents' domain judgments, either harmfulness or decision-making (who decides), were entered into step three of the model. In the final step of the model, interactions between the discrepancy of female caregivers' and adolescents' domain judgments and adolescent body image dissatisfaction, nutrition knowledge scores, and age were entered.

The first model examined associations between the discrepancy of female caregivers' and adolescents' domain judgments and over-eating behaviors (DEBQ - Emotional and External Eating Subscales). Two significant interactions emerged (Table 8). First, a significant discrepancy by age interaction indicated that increased disagreement between female caregivers' and adolescents' decision-making judgments about food-related behavior was associated with increased over-eating behavior in younger adolescents, but not older adolescents (Figure 1: Younger adolescents: $\mathrm{B}=.23, \mathrm{SE}=.11, p=.03$; Older Adolescents: $\mathrm{B}=-.07, S E=.11, p=\mathrm{ns}$ ). Second, a significant discrepancy by body image dissatisfaction interaction indicated that increased disagreement between female caregivers' and adolescents' harmfulness ratings of food-related behavior was associated with decreased over-eating behavior for adolescents who were more satisfied with their bodies compared to adolescents who were not satisfied with their 
bodies (Figure 2: High body image satisfaction: $\mathrm{B}=-.22, S E=.08, p=.009$; Low body image satisfaction: $\mathrm{B}=.15, \mathrm{SE}=.10, p=\mathrm{ns})$.

The second model examined the association between the discrepancy of female caregivers' and adolescents' domain judgments and under-eating behaviors (DEBQ - Restrained Eating Subscale). There was a significant main effect of adolescents' body image dissatisfaction $(\beta=.31, p=.001)$, indicating that increased body image dissatisfaction was associated with increased under-eating behavior. No significant interactions emerged (Table 9).

\section{Discussion}

The purpose of the current study was to examine age-related differences in adolescents' domain beliefs about food-related issues, differences between female caregivers' and adolescents' domain judgments, and associations between adolescents' domain beliefs about food-related behavior and their engagement in problematic eating patterns. An additional exploratory research question examined associations between discrepancies in female caregivers' and adolescents' domain beliefs about food-related behavior and adolescent problematic eating outcomes. The current study is important because previous social domain research has yet to examine food/eating behavior as a multifaceted issue or associations between adolescents' domain beliefs about food and engagement in problematic eating behavior.

\section{Female Caregivers' and Adolescents' Domain Beliefs about Food/Eating Behavior}

In the current study, it was hypothesized that older adolescents would rate food-related behaviors as less harmful and requiring less parental input than younger adolescents. It was also hypothesized that female caregivers would rate adolescent eating behaviors as more harmful than adolescents, and female caregivers would rate adolescent eating behavior as requiring more parental input and decision-making than adolescents. These two hypotheses were partially 
supported; older adolescents reported food-related decisions as personal issues (requiring less parental input) compared to early adolescents, yet these two groups did not significantly differ in their harmfulness ratings of food and eating behavior. Similarly, female caregivers and adolescents did not significantly differ in their harmfulness ratings of food and both groups reported food-related behaviors to be moderately harmful. However, female caregivers did rate adolescent eating behaviors as requiring more parental input, while adolescents viewed this issue as personal and up to the adolescent to decide (Tables $4 \& 5$ ).

The significant difference between female caregivers' and adolescents' decision-making judgments about adolescent eating behaviors was consistent with previous social domain research suggesting age-related changes in adolescent conceptualization of multifaceted issues (Smetana, 1989; Nucci, 1981, Smetana \& Asquith, 1994; Smetana, 2002; Smetana, CampioneBarr, \& Daddis, 2004; Turiel, 1989). In the current study, older adolescents viewed adolescent eating as an area of personal jurisdiction, and an issue that is up to them to decide more so than early adolescents. This finding highlights normative development during adolescence (Smetana, 2002; Smetana, Campione-Barr, \& Metzger, 2006); older adolescents have gained increased autonomy from female caregivers and now view multifaceted issues, like food and eating, as personal and up to them to decide. Additionally, adolescents, regardless of age, viewed decisions about food and eating as requiring less input from female caregivers, while female caregivers reported decisions about such behaviors as requiring more parental decision-making. These findings indicate that female caregivers grant more autonomy for food-related decision-making as adolescents age; however, consistent with previous research (Smetana, Campione-Barr, \& Daddis, 2004; Smetana \& Daddis, 2002) about other multifaceted issues, adolescents are still ahead of female caregivers in terms of when they believe autonomy is granted. 
Both female caregivers and adolescents, and early and late adolescents, had similar harmfulness ratings of food-related behavior; both groups attributed a moderate amount of risk to various eating behaviors, including eating junk food and snacks between meals. This finding, although non-significant, is important because it suggests that female caregivers and adolescents have similar understandings of the level of risk associated with unhealthy eating practices. It also suggests that adolescents establish their views about food harmfulness at an early age, potentially as early as childhood. Female caregivers have the ability to impact their child's socialization of such beliefs about food. For example, Nucci and Smetana (1996) discussed how conflict over eating begins early in development, and that parents and children agree that decisions about "favorite foods" fall into the personal domain. Although parents and children may agree on this aspect of eating, parents may also emphasize distinctions between what foods are considered healthy and what foods are unhealthy during this stage of development, and both groups may continue to subscribe to these views as they mature. Furthermore, socialization of healthy/unhealthy eating practices may also occur outside the home, and take place through classes at the high/middle school. Obesity rates are on the rise, and as a result, the school system may implement information about healthy eating (nutrition) and exercise techniques into the curriculum. Finally, these findings also suggest that differences in female caregivers' and adolescents' conceptualizations of food-related behavior focus on the conventional-personal domain distinction; both female caregivers and adolescents recognize the prudential aspects of unhealthy eating behavior. As a result, female caregivers' and adolescents' competing interpretations of food-related behavior from the conventional and personal domains, respectably, may ultimately be the factor driving developmental processes toward independent eating behavior during adolescence. 
Lastly, it was hypothesized that mean differences between female caregivers' and adolescents' domain judgments would vary by adolescent age. This hypothesis was not supported; differences in female caregivers' and adolescents' harmfulness and decision-making judgments did not vary as a function of adolescent age. However, the interaction between decision-making and age was trending in the hypothesized direction; with increasing adolescent age, female caregivers were more likely to view food-related decisions as up to teenagers to decide (Figure 3). This non-significant trend could have resulted for several reasons. Previous research has found that adolescents do spend more time away from parents at meal and snack time, which increases opportunities for adolescents to have a larger say in their eating behavior (Eisenberg \& Neumark-Sztainer, 2010; Jung \& Forbes, 2006; Libbey et al., 2008; Meyer \& Gast, 2008; Saules et al., 2009). However, parents are still often in-charge of the majority of food and eating-related decisions for the family, such as purchasing food that is bought for meals prepared at home or the actual meal preparation. Taking sole responsibility of grocery list preparation, shopping and additional meal time duties, including preparing and serving food may be areas adolescents do not have the ability to take sole control over until later stages of development. In addition, parents may not want to grant adolescents complete autonomy over these areas because they do not believe they are ready to make healthy, informed choices about food and eating at this point in development. Thus, the trajectory toward solely autonomous decision-making about food-related issues may not occur until adolescents leave the family unit in emerging adulthood. Young adults are less dependent on parents to make daily food-related decisions; they are required to make the majority of these decisions on their own. 
It was also hypothesized that adolescents' domain beliefs about food would be associated with problematic eating, and that these associations would be moderated by several factors, including adolescent age, level of nutrition knowledge, and body image dissatisfaction. No significant interactions resulted, but harmfulness ratings were directly associated with undereating and decision-making judgments were directly associated with over-eating. These findings stress the potential importance of examining inter-individual differences in adolescents' domainspecific judgments when predicting problematic eating outcomes.

In the current study, viewing food and eating as harmful was associated with under-eating behavior. The scale used to measure under-eating behavior (DEBQ; van Strien et al., 1986) references actions including, eating less at mealtimes than one would like to eat and refusing food and drinks when offered. These items detail strategies, although not uncommonly implemented, that would be considered unhealthy and restrictive actions that individuals may use to manage their weight and body size. As a result, these findings illustrate a concordance between viewing food and eating as harmful and potentially maladaptive, weight-regulation strategies during adolescence. Furthermore, being hypersensitive to the risks associated with various food-related behaviors may influence adolescents to approach food with increased caution; this wariness of food may lead to additional problematic outcomes, including restrictive or under-eating. The current results indicate that some adolescents do view food as overly harmful and risky, and as a result, their actual eating behavior is affected in a potentially negative, unhealthy manner. Comparisons between adolescents who are hypersensitive to food risks and same-aged peers who do not view food-related behavior in this way may reveal additional differences in the trajectory of problematic eating during adolescence. 
This finding is also important because adolescents' harmfulness views of food predicted under-eating behavior over and above teens' level of body image dissatisfaction (Table 7). Previous research (Jung \& Forbes, 2006; Saules et al., 2009; Wood \& Petrie, 2010) has found an association between body image dissatisfaction and problematic eating, and the current study replicates those findings. However, adolescents' harmfulness ratings of food-related behavior were not significantly correlated with their ratings of body image dissatisfaction (Table 3) which suggests that two competing beliefs systems may act independently in predicting adolescents' engagement in under-eating. The first system involves adolescents' beliefs about their body image and size compared to cultural standards of ideal beauty. Adolescents who are dissatisfied with how they look implement practices, like under-eating, to achieve a desired body image (Botta, 2003; Erol, Toprak, \& Yazici, 2006). The current findings indicate that hypersensitivity and preoccupation with the harmfulness and risk associated with food may constitute a second belief system influencing engagement in under-eating behavior. As a result, adolescents who view food as increasingly harmful may approach food with greater caution and restrict their diet.

In contrast, increased adolescent unilateral decision-making, with little parental input, was associated with increased over-eating behavior. This finding suggests that adolescents who make the majority of the decisions about food and eating without parental input may be less likely to make healthy choices and engage in over-eating behavior. Parental involvement may protect adolescents from engaging in unhealthy, over-eating practices during this developmental time period. This finding may also have practical implications for all parents; increased parentadolescent joint decision-making about food-related behaviors may minimize adolescents' risks for poor over-eating behaviors, which lead to obesity, including engagement in emotional or external eating practices. Thus, increased parental regulation of eating concerning adolescents' 
decision-making about food-related issues may be an important mechanism through which parents can help reduce adolescent engagement in over-eating activities.

Under- and over-eating behaviors appear to have different developmental trajectories during adolescence. Under-eating behavior is influenced by adolescents' body image concerns as well as their hypersensitivity to the risks associated with various food-related behaviors, while over-eating is impacted by decreased parental input and increased adolescent unilateral decisionmaking about eating. These results indicate that different problematic eating trajectories may be associated with adolescents' varying social cognitive interpretations (harm versus decisionmaking) of food-related behavior. Overall, viewing over-eating as overly personal (rather than conventional and regulated by parents) or overly prudential (harmful) may be associated with distinctive (over- versus under-eating) adverse eating outcomes. Future studies should continue to consider adolescents' domain belief differences and domain specific reasoning in conjunction with various problematic eating patterns when examining the association between one's beliefs and behavior.

\section{The Discrepancy between Female Caregivers' and Adolescents' Domain Beliefs about Food/Eating Behavior and Adolescent Problematic Eating Patterns}

Finally, it was hypothesized that the discrepancy or disagreement between female caregivers' and adolescents' domain beliefs about food-related behavior would be associated with adolescents' engagement in problematic under- or over-eating, and that these associations would be moderated by adolescent age, nutrition knowledge and body image dissatisfaction. Results indicated that increased disagreement about who makes decisions about food/eating behavior was associated with problematic over-eating for early adolescents, but not late adolescents (Figure 1). These results are consistent with previous research (Sher-Censor et al., 
2011), which examined discrepancies in Mexican American parent-adolescent dyads' perceptions of parental autonomy promotion and adolescent adjustment. These researchers found the discrepancy in parents' and adolescents' perceptions of autonomy to be associated with increased depressive symptoms in boys and girls, and decreased views of self-worth in adolescent females. Disagreement over who makes decisions about various issues may impact adolescents' psychological well-being. Similar disagreements may occur in reference to foodrelated decisions, especially problematic over-eating behavior during early adolescence. In the current study, early adolescents attribute more parental input and authority to decisions about food compared to older adolescents, and regardless of adolescent age, parents still believed decision-making about food-related behavior requires more parental input. As a result, disagreements over who actually makes decisions about food may influence problematic outcomes for early adolescents who believe they should be in-charge of regulating their diet without parents' guidance.

Interestingly, increased disagreement between female caregivers' and adolescents' harmfulness ratings of food-related behavior was associated with decreased over-eating behavior for adolescents who were more satisfied with their bodies (Figure 2). Adolescents who were satisfied with their bodies and who also rated food as more harmful compared to female caregivers were more likely to over-eat. However, when female caregivers rated food as more harmful than adolescents, and adolescents were satisfied with their bodies, a decrease in overeating behavior was observed. One potential explanation for this finding is that parents' harmfulness ratings are linked to specific parenting behaviors. If parents rate food as increasingly harmful, they may enact strategies, such as not purchasing junk food or soliciting information about what their teenager eats outside the home to monitor eating behavior. The use of such 
tactics may impact adolescents' ability to over-eat. Furthermore, these findings suggest that parents may play a unique role in the development of adolescents' attitudes toward the risks associated with unhealthy eating as well as adolescents' actual engagement in problematic eating patterns, like over-eating. Future research should examine associations between parents' domain beliefs regarding eating and specific eating-related parenting practices in order to better understand how parents' beliefs impact adolescents engagement in healthy or unhealthy eating practices.

\section{Limitations}

The results of this study should be interpreted in light of several limitations. One limitation is the use of a correlational study design preventing discussions of causality between the predictor and outcome variables. Due to the fact that the associations found in the current study are concurrent, the direction of the effects is not known. A third, unmeasured variable could also account for these associations. Additionally, cross-sectional analyses do not allow for the examination of intra-individual change in study variables over time.

The use of self-report survey measures for both female caregivers and adolescents is also a limitation. Self-report survey measures are subject to socially desirable responses, and female caregivers and adolescents may have felt uncomfortable answering questions about sensitive topics, such as junk food consumption, snacking between meals, dieting behavior and which family members make most of the decisions about food. Multiple reporters were used and comparisons were made between female caregivers' and adolescents' domain beliefs; however, previous research (Fulkerson et al., 2006) found discrepancies between parents' and adolescents' reports of frequency of mealtimes spent together and the importance of eating together as a family. As a result, additional reports from siblings and peer groups may be necessary to gain a 
complete picture of the developmental trajectory of healthy versus unhealthy eating established during adolescence.

The items used to assess female caregivers' and adolescents' harmfulness ratings of food exhibited poor reliability; Cronbach's $\alpha=.58$ and .46 respectably. Because this was the case, a revised version of the female caregiver and adolescent harmfulness subscales were used, and the item assessing the harmfulness of dieting behavior was dropped. The revised scales contained three items, which measured the harmfulness of over-eating behaviors, such as eating junk food and snacking between meals, and they still had poor reliability (Female caregivers: $\alpha=.54$; Adolescents: $\alpha=.59$ ). The poor reliability seen with the full subscale may have resulted because both over- and under-eating, were being measured with one subscale; potentially, female caregivers' and adolescents' harmfulness ratings of under eating may differ from their ratings of over-eating. In future research, separate harmfulness subscales should be used to assess the harmfulness associated with under- versus over-eating.

Lastly, characteristics of the sample may limit generalizability of the findings. The current study only examined female caregiver-adolescent dyads and the current findings may differ for father-adolescent relationships. Previous work (Daddis \& Smetana, 2005) found that mothers and fathers have similar expectations for the timing of behavioral autonomy about a number of issues in adolescents' lives. However, other research indicates that fathers may play a unique role in adolescent development (Fosco et al., 2012). Fathers may view food-related issues from different domains of social knowledge when compared to female caregivers. Furthermore, the female caregivers in this sample were highly educated and from high SES backgrounds; $76.5 \%$ of the sample had at least a bachelor's degree, and $27.5 \%$ of the sample had a doctoral or professional degree, while $87.2 \%$ reported a yearly income of greater than $\$ 25,000$. Previous 
research (Lowry et al., 1996; Story et al., 2002; Walcott et al., 2003) has found associations between parental education level, family SES, and healthy eating patterns during adolescence. As a result, the findings from the current study may have limited generalizability to families where female caregivers have fewer years of formal education or to families from low SES backgrounds.

Self-selection of adolescent participants into the sample may have also impacted the findings. The current sample was primarily female (62.7\%), Caucasian/White (70.6\%) and consisted of adolescents who earned higher GPA's in school (38.2\% earned Mostly A's). Different types of adolescents, particularly females or those who earn high grades in school may be more motivated to take part in research projects, which limits the generalizability of the findings to males and adolescents who do not earn high GPA's. Furthermore, the current study was part of a larger, on-going project examining family communication; parents and adolescents had to participate in a short video-interaction task as part of the larger study. Therefore, adolescent participants in this study may represent a small, sub-sample of adolescents who feel comfortable talking about a number of issues with their parents.

\section{Implications and Future Directions}

The results of this study have several implications for future research, as well as for parents, adolescents, and the development of healthy eating patterns during adolescence. The current study expands on previous work using social domain theory by examining differences in female caregivers' and adolescents' decision-making judgments and harmfulness ratings about food-related issues, as well as associations between adolescents' domain judgments about food and their engagement in problematic eating behaviors. Future studies should continue to explore parents' and adolescents' domain judgments about different aspects of eating, and the association 
between both parents' and adolescents' beliefs about food and adolescent engagement in problematic eating patterns. Longitudinal studies would provide information about how parents' and adolescents' domain beliefs about food-related issues change over the course of adolescence. In addition, longitudinal data would allow for the use of more complex models examining intraindividual change in domain beliefs about food-related behaviors and predictors of interindividual differences in intra-individual change.

Consistent with previous research, the current study examined whether differences in female caregivers' and adolescents' decision-making varied as a function of adolescent age, and the resulting interaction was trending in the hypothesized direction (Figure 3). Future research should consider including emerging adults, as the current findings indicate that the transition to adulthood may be an important time period to study domain beliefs about food-related issues. In comparison to adolescents, young adults may no longer be dependent on parents for mealtime decisions and food choices resulting in different domain beliefs about food and eating practices.

Future studies should also examine adolescent gender as a potential moderator to parents' and adolescents' decision-making and harmfulness domain judgments about food. Previous research (Nunez-Navarro et al., 2011) indicates clinically-diagnosed females score higher on harm avoidance measures compared to samples of clinically-diagnosed, young adult males. Females from non-clinical samples may also attribute more harm to food because of changes in cultural standards of beauty (Singh \& Singh, 2011), especially increased publication of the thin ideal (Borzekowski et al., 2000; Calado et al., 2011). Being over-weight places females farther away from the ideal body size/shape deemed by society, and such culturally communicated ideals may be associated with adolescent girls' views of food as increasingly harmful, leading to restrictive eating practices. Adolescent boys do not have to contend with the thin ideal quite as 
much as females. However, recent research (Hatoum \& Belle, 2004; McCabe \& Riccaridelli, 2004) has examined the detrimental impact of the "muscular ideal," and its association with body image dissatisfaction in adolescent males. In addition, adolescents' BMI may also differentially impact parents' and adolescents' decision-making judgments and harmfulness ratings of food, regardless of adolescent gender. Specifically, viewing food as overly harmful may be associated with problematic outcomes for adolescents who are classified as underweight, while viewing decision-making about food as solely personal may be problematic for adolescents who are overweight.

Lastly, future studies should examine whether parents' beliefs about food-related issues predict adolescents' engagement in problematic eating. Previous research indicates that dysfunctional family relationships, or ones with decreased cohesion, have been linked to the development of problematic eating patterns during adolescence (Epstein et al., 1994; Mellin et al., 2002). Problematic eating patterns may also result in families with inappropriate parental decision-making about issues that adolescents view as up to them to decide, and adolescents may use unhealthy under- or over-eating behaviors as a means to exert control over this area of their life or to rebel against parental authority. In addition, research should consider other parenting behaviors such as rule setting, psychological control approaches, and covert (e.g. inspecting amount of junk food in the house) and overt (e.g. asking teens if they eat junk food) monitoring strategies because parents' use of such tactics to gain knowledge about adolescents' eating behavior may be associated with adolescents' engagement in problematic eating practices, including secretive eating.

Unhealthy eating patterns and obesity are on the rise in today's youth (Ogden \& Carroll, 2010), and the results of future studies in this area can be used to inform medical professionals 
about antecedents of more severe problematic eating behaviors that have origins in childhood and adolescence. The current study's findings indicate that the way normatively developing adolescents' conceptualize food-related issues (personal versus conventional versus prudential domains) impacts their engagement in different aspects of problematic eating. Overall, these results suggest further use of the social-cognitive framework for examination of correlates of problematic eating during adolescence. 


\section{References}

American Psychiatric Association (APA) (2000). Diagnostic and statistical manual of mental disorders ( $4^{\text {th }}$ ed., text revision). Washington, DC: Author.

Arnett, J.J. (1999). Adolescent storm and stress, reconsidered. American Psychologist, 54(5), 317-326.

Arnett, J.J. (2001). Conceptions of the transition to adulthood: Perspectives from adolescence through midlife. Journal of Adult Development, 8(2), 133-143.

Arnett, J.J., \& Taber, S. (1994). Adolescence terminable and interminable: When does adolescence end? Journal of Youth and Adolescence, 23(5), 517-537.

Botta, R. A. (2003). The relationship between magazine reading and adolescents' body image and eating disturbances. Sex Roles, 48, 389399.23-33.

Calado, M., Lameiras, M., Sepulveda, A.R., Rodriguez, Y., \& Carrera, M.V. (2010). The mass media exposure and disordered eating behaviors in Spanish secondary students. European Eating Disorders Review, 18(5), 417-427.

Chen, K., Lay, K., \& Wu, Y. (2005). The developmental differences of identity content and exploration among adolescents of different stages. Chinese Journal of Psychology, 47(3), $268-286$.

Daddis, C., \& Smetana, J.G. (2005). Middle-class African American families' expectations for adolescents' behavioral autonomy. International Journal of Behavioral Development, 29(5), 371-381.

Dowdell, E.B., \& Santucci, M.E. (2004). Health risk behavior assessment: Nutrition, weight and tobacco use in one urban seventh-grade class. Public Health Nursing, 21(2), 128-136.

Duncan, M., Dodd, L., \& Al-Nakeeb, Y. (2005). The impact of silhouette randomization on the 
results of figure rating scales. Measurement in Physical Education and Exercise Science, 9(1), 61-66.

Eisenberg, M.E., \& Neumark-Sztainer, D.R. (2010). Friends' dieting and disordered eating behaviors among adolescents five years later: Findings from Project EAT. Journal of Adolescent Health, 47, 67-73.

Epstein, L. H., Klein, K. R., \& Wisniewski, L. (1994). Child and parent factors that influence psychological problems in obese children. International Journal of Eating Disorders, 15, $151-157$

Erol, A., Toprak, G., \& Yazici, F. (2006). Psychological and physical correlates of disordered eating in male and female Turkish college students. Psychiatry and Clinical Neurosciences, 60, 551-557.

Fosco, G.M., Stormshak, E.A., Dishion, T.J., \& Winter, C.E. (2012). Family relationships and parental monitoring during middle school as predictors of early adolescent problem behavior. Journal of Clinical Child \& Adolescent Psychology, 41(2), 202-213.

Franko, D.L., \& Omori, M. (1999). Subclinical eating disorders in adolescent women: A test of the continuity hypothesis and its psychological correlates. Journal of Adolescence, 22, 389-396.

Frazier, P., Tix, A., \& Barron, K. (2004). Testing moderator and mediator effects in counseling psychology research. Journal of Counseling Psychology, 51, 115-134.

Freud, A. (1946). The ego and the mechanisms of defense. New York: International Universities Press.

Freud, S. (1953). A general introduction to psychoanalysis. New York: Permabooks.

Fulkerson, J.A., Neumark-Sztainer, D., \& Story, M. (2006). Adolescent and parent views of family meals. Journal of the American Dietetic Association, 106(4), 526-532. 
Hall, G.S. (1916). Adolescence. New York: Appleton.

Hatoum, I.J., \& Belle, D. (2004). Mags and abs: Media consumption and bodily concerns in men. Sex Roles, 51(7-8), 397-407.

Jung, J., \& Forbes, G.B. (2006). Multidimensional assessment of body dissatisfaction and disordered eating in Korean and US college women: A comparative study. Sex Roles, 55(1-2), 39-50.

Kjelsas, E., Bjornstrom, C., \& Gotestam, K.G. (2004). Prevalence of eating disorders in female and male adolescents (14-15 years). Eating Behaviors, 5, 13-25.

Larson, R.W., Richards, M.H., Moneta, G., Holmbeck, G. \& Duckett, E. (1996). Changes in adolescents' daily interactions with their families from ages 10 to 18: Disengagement and transformation. American Psychological Association, 32(4), 744-754.

Libbey, H.P., Story, M.T., Neumark-Sztainer, D.R., \& Boutelle, K.N. (2008). Teasing, disordered eating behaviors, and psychological morbidities among overweight adolescents. Obesity, 16, 24-29.

Lohaus, A., Vierhaus, M., \& Ball, J. (2009). Parenting styles and health-related behavior in childhood and early adolescence: Results of a longitudinal study. The Journal of Early Adolescence, 29(4), 449-475.

Lowry, R., Kann, L., Collins, J.L., \& Kolbe, L.J. (1996). The effect of socioeconomic status on chronic disease risk behaviors among US adolescents. JAMA, 276(10), 792-797.

McCabe, M.P., \& Ricciardelli, L.A. (2004). Body image dissatisfaction among males across the lifespan: A review of past literature. Journal of Psychosomatic Research, 56(6), 675-685.

Mellin, A. E., Neumark-Sztainer, D., Story, M., Ireland, M., \& Resnick, M. D. (2002).Unhealthy 
behaviors and psychosocial difficulties among overweight adolescents: The potential impact of familial factors. Journal of Adolescent Health, 31, 145-153.

Metzger, A., \& Smetana, J. (2009). Adolescent civic and political engagement: Associations between domain-specific judgments and behavior. Child Development, 80(2), 433-441.

Meyer, T.A., \& Gast, J. (2008). The effect of peer influence on disordered eating behavior. The Journal of School Nursing, 24, 36-42.

Mintz, L.B., \& Betz, N.E. (1988). Prevalence and correlates of eating disordered behaviors among undergraduate women. Journal of Counseling Psychology, 35(4), 463-471.

Nucci, L. (1981). The development of personal concepts: A domain distinct from moral or societal concepts. Child Development, 52, 114-121.

Nucci, L.P., Guerra, N., \& Lee, J. (1991). Adolescent judgments of the personal, prudential, and normative aspects of drug usage. Developmental Psychology, 27, 841-848.

Nucci, L.P., \& Smetana, J. (1996). Mothers' conceptions of young children's areas of personal freedom. Child Development, 67, 1870-1886.

Nunez-Navarro, A., Aguera, Z., Krug, I., Jimenez-Murcia, S., Sanchez, I., Araguz, N., Gorwood, P., Granero, R., Penelo, E., Karwautz, A., Moragas, L., Saldana, S., Treasure, J., Menchon, J.M., \& Fernandex-Aranda, F. (2011). Do men with eating disorders differ from women in clinics, psychopathology and personality? European Eating Disorders Review, 20, 23-31.

O’Dea, J. (1994). Food habits, body image and self-esteem of adolescent girls from disadvantaged and non-disadvantaged backgrounds. Australian Journal of Nutrition and Dietetics, 51, 74-78.

O’Dea, J., \& Caputi, P. (2001). Association between socioeconomic status, weight, age and 
gender, and the body image and weight control practices of 6 to 19 year-old children and adolescents. Health Education Research, 16(5), 521-532.

Ogden, C., \& Carroll, M. (2010). Prevalence of obesity among children and adolescents: United States, trends 1963-1965 through 2007-2008. Center for Disease Control: National Center for Health Statistics, 1-5.

Parmenter, K., \& Wardle, J. (1999). Development of a general nutrition knowledge questionnaire for adults. European Journal of Clinical Nutrition, 53, 298-308.

Parmenter, K., \& Wardle, J. (2000). Nutrition knowledge and food intake. Appetite, 34, 269-275.

Peck, L.D., \& Lightsey, O.R. (2008). The eating disorders continuum, self-esteem, and perfectionism. Journal of Counseling \& Development, 86, 184-192.

Platte, P., Zelten, J.F., \& Stunkard, A.J. (2000). Body image in the older order Amish: A people separate from 'the world'. International Journal of Eating Disorders, 28(4), 408-414.

Saules, K.K., Collings, A.S., Wiedemann, A.A., \& Fowler, S.L. (2009). The relationship of body image to body mass index and binge eating: The role of cross-situational body image dissatisfaction versus situational reactivity. Psychological Reports, 104(3), 909-921.

Schwartz, S.J., \& Pantin, H. (2006). Identity development in adolescence and emerging adulthood: The interface of self, context, and culture. In A. Columbus (Ed.) Advances in Psychology Research (pp. 1-40). Hauppauge, NY: Nova Science Publishers.

Sher-Censor, E., Parke, R.D., \& Coltrane, S. (2011). Parents promotion of psychological autonomy, psychological control, and Mexican-American adolescents' adjustment. Journal of Youth Adolescence, 40, 620-632.

Singh, D., \& Singh, D. (2011). Shape and significance of feminine beauty: An evolutionary perspective. Sex Roles, 64, 723-731. 
Shisslak, C.M., Crago, M., \& Estes, L.S. (1994). The spectrum of eating disturbances. International Journal of Eating Disorders, 18(3), 209-219.

Smetana, J.G. (1981). Reasoning in the personal and moral domains: Adolescent and young women's decision-making regarding abortion. Journal of Applied Developmental Psychology, 2(3), 211-226.

Smetana, J.G. (1988). Adolescents' and parents' conceptions of parental authority. Child Development, 59, 321-335.

Smetana, J.G. (1989). Adolescents' and parents' reasoning about actual family conflict. Child Development, 60, 1052-1067.

Smetana, J. (1989a). Toddlers' social interactions in the context of moral and conventional transgressions in the home. Developmental Psychology, 25, 499-508.

Smetana, J.G. (1992). Understanding of social rules. In M. Bennett (Ed.) The child as psychologist. (pp.111-141). London: Harvester-Wheatsheaf.

Smetana, J.G. (1993). Conceptions of parental authority in divorced and married mothers and their adolescents. Journal of Research in Adolescence, 3, 19-40.

Smetana, J.G. (1995). Context, conflict, and constraint in parent0adolescent authority relationships. In M. Killen \& D. Hart (Eds.). Morality in everyday life: Developmental perspectives (pp. 225-255). Cambridge, MA: Cambridge Univ. Press.

Smetana, J.G. (1995a). Parenting styles and conceptions of parental authority during adolescence. Child Development, 66, 299-316.

Smetana, J.G. (2002). Culture, autonomy, and personal jurisdiction in adolescent-parent relationships. Advances in Child Development and Behavior, 29, 51-87.

Smetana, J.G., \& Asquith, P. (1994). Adolescents' and parents' conceptions of parental authority 
and personal autonomy. Child Development, 65, 1147-1162.

Smetana, J.G, \& Bitz, B. (1996). Adolescents' conceptions of teachers' authority and their relations to rule violations in school. Child Development, 67(3), 1153-1172.

Smetana, J.G., Campione-Barr, N., \& Daddis, C. (2004). Longitudinal development of family decision making: Defining healthy behavioral autonomy for middle-class African American adolescents. Child Development, 75(5), 1418-1434.

Smetana, J.G., Campione-Barr, N., \& Metzger, A. (2006). Adolescent development in interpersonal and societal contexts. Annual Review of Psychology, 57, 255-284.

Smetana, J.G., Crean, H.F., \& Daddis, C. (2002). Family processes and problem behaviors in middle-class African American Adolescents. Journal of Research on Adolescence, 12(2), 275-304.

Smetana, J.G, \& Daddis, C. (2002). Domain-specific antecedents of psychological control and parental monitoring: The role of parenting beliefs and practices. Child Development, 73, $563-580$.

Steinberg, L., \& Morris, A.S. (2001). Adolescent development. Annual Review of Psychology, 52, 83-110.

Story, M., Neumark-Sztainer, D., \& French, S. (2002). Individual and environmental influences on adolescent eating behaviors. Supplement to the Journal of The American Dietetic Association, 102(3), S40-S51.

Stunkard, A., Sorenson, T., \& Schulsinger, F. (1983). Use of the Danish adoption register for the study of obesity and thinness. In: Kety S., Rowland, L., Sidman, R., \& Mathysse, S. (Eds.) Genetics of Neurological and Psychiatric Disorders (pp. 115-120). New York: Raven Press. 
Swami, V., Taylor, R., \& Carvalho, C., (2011). Body dissatisfaction assessed by the photographic figure rating scale is associated with sociocultural, personality, and media influences. Scandinavian Journal of Psychology, 52(1), 57-63.

Tisak, M.S., \& Turiel, E. (1984). Children's conceptions of moral and prudential rules. Child Development, 55(3), 1030-1039.

Turiel, E. (1989). Domain-specific social judgments and domain ambiguities. Merrill-Palmer Quarterly, 35(1), 89-114.

Turiel, E., Hildebrandt, C., \& Wainryb, C. (1991). 'Children's reasoning about complex social issues.' Monographs of the Society for Research in Child Development, 56(2) (Serial \#224).

van Strien, T., Frijters, J.E., Bergers, G.P., \& Defares, P.B. (1986). The Dutch Eating Behavior Questionnaire (DEBQ) for assessment of restrained, emotional, and external eating behavior. International Journal of Eating Disorders, 5(2), 295-315.

Walcott, D.D., Pratt, H.D., \& Patel, D.R. (2003). Adolescents and eating disorders: Gender, racial, ethnic, sociocultural, and socioeconomic issues. Journal of Adolescent Research, $18(3), 223-243$

Wood, N., \& Petrie, T. (2010). Body dissatisfaction, ethnic identity, and disordered eating among African American women. Journal of Counseling Psychology, 57(2), 141-153. 


\section{Table 1}

\section{Adolescent demographic descriptive statistics}

\begin{tabular}{|c|c|c|c|}
\hline Measure & & $\mathrm{M}(S D)$ & $\%$ \\
\hline \multicolumn{4}{|l|}{ Gender } \\
\hline- & Males & & 37.3 \\
\hline - & Females & & 62.7 \\
\hline \multicolumn{4}{|l|}{ Age } \\
\hline & & $14.65(1.57)$ & \\
\hline \multicolumn{4}{|l|}{ Ethnicity } \\
\hline - & African American/Black & & 4.9 \\
\hline- & Asian American/Pacific Islander & & 1.0 \\
\hline- & Native American & & \\
\hline - & Hispanic/Latino & & 1.0 \\
\hline - & Caucasian/White & & 2.9 \\
\hline- & Biracial & & 70.6 \\
\hline- & Missing/Failed to Report & & 14.7 \\
\hline & & & 2.9 \\
\hline \multicolumn{4}{|l|}{ GPA } \\
\hline - & Mostly A’s & & 38.2 \\
\hline - & Some A's, Mostly B's & & 31.4 \\
\hline - & Mostly B's & & 3.9 \\
\hline- & Some B's, Some C's & & 18.6 \\
\hline- & Mostly C's & & 1.0 \\
\hline - & Some C's, Some D's & & 3.9 \\
\hline- & Missing/Failed to Report & & 2.9 \\
\hline
\end{tabular}

Body Image

- Currently Look

- $\quad$ Ideal Look

Nutrition Knowledge

Parental Restrictive Control

Harmfulness Scale

Harmfulness Scale Revised

Over-eating Scale

Dutch Eating Behavior Subscales

- $\quad$ Restrained (Under-eating Scale)

- Emotional

- External
$4.20(1.26)$

$3.46(0.96)$

$19.11(4.91)$

$9-32$
$2.08(0.74)$

$3.17(0.73)$

$3.16(.77)$

$2.55(0.62)$

$2.38(0.85)$

$2.11(0.87)$

$2.99(0.58)$ 
Table 2

Female caregiver demographic descriptive statistics

\begin{tabular}{|c|c|c|}
\hline Measures & $\mathbf{M}(S D)$ & $\%$ \\
\hline Age & $43.79(7.14)$ & \\
\hline $\begin{array}{cl}\text { Education Level } \\
\text { - } & \text { Completed } 8^{\text {th }} \text { Grade } \\
- & \text { Completed High School } \\
- & \text { Completed College } \\
\text { - } & \text { Business or Technical School } \\
\text { - } & \text { Graduate Degree (Doctor, Lawyer, PhD) } \\
- & \text { Missing }\end{array}$ & & $\begin{array}{c}1.0 \\
21.6 \\
36.3 \\
12.7 \\
27.5 \\
1.0\end{array}$ \\
\hline $\begin{array}{cl}\text { Relationship to Adolescent } \\
\text { - } & \text { Birth Mother } \\
\text { - } & \text { Step-Mother } \\
\text { - } & \text { Adoptive Mother } \\
\text { - } & \text { Grandparent } \\
\text { - } & \text { Other Relative (aunt, sister, cousin) } \\
\text { - } & \text { Guardian }\end{array}$ & & $\begin{array}{c}94.1 \\
1.0 \\
2.0 \\
1.0 \\
1.0 \\
1.0\end{array}$ \\
\hline $\begin{array}{cl}\text { Marital Status } \\
\text { - } & \text { Married } \\
\text { - } & \text { Divorced/Separated } \\
\text { - } & \text { Widowed } \\
\text { - } & \text { Single, Never Married } \\
\text { - } & \text { Living with a Romantic Partner } \\
\text { - } & \text { Missing }\end{array}$ & & $\begin{array}{c}73.5 \\
16.7 \\
2.9 \\
2.9 \\
2.0 \\
2.0\end{array}$ \\
\hline $\begin{array}{cc}\text { Employment } \\
- & \text { Yes, Full-Time } \\
- & \text { Yes, Part-Time } \\
- & \text { No }\end{array}$ & & $\begin{array}{l}52.0 \\
19.6 \\
28.4\end{array}$ \\
\hline $\begin{array}{cl}\text { Ethnicity } & \\
\text { - } & \text { African American/Black } \\
\text { - } & \text { Asian-American/Pacific Islander } \\
\text { - } & \text { Caucasian/White } \\
\text { - } & \text { Hispanic/Latino } \\
\text { - } & \text { Native American }\end{array}$ & & $\begin{array}{c}4.9 \\
1.0 \\
91.2 \\
2.0 \\
1.0\end{array}$ \\
\hline $\begin{array}{cl}\text { Income } & \\
\text { - } & \$ 11,999 \text { or less } \\
\text { - } & \$ 12,000 \text { to } \$ 24,999 \\
\text { - } & \$ 25,000 \text { to } \$ 49,999 \\
\text { - } & \$ 50,000 \text { to } \$ 74,999 \\
\text { - } & \$ 75,000 \text { to } \$ 99,999 \\
\text { - } & \$ 100,000 \text { to } \$ 149,999 \\
\text { - } & \$ 150,000 \text { or above } \\
\text { - } & \text { Missing }\end{array}$ & & $\begin{array}{r}3.9 \\
5.9 \\
21.6 \\
18.6 \\
17.6 \\
16.7 \\
12.7 \\
2.9\end{array}$ \\
\hline Decision Making Scale & $2.56(0.76)$ & \\
\hline Harmfulness Scale & $3.24(0.65)$ & \\
\hline Harmfulness Scale Revised & $3.14(.66)$ & \\
\hline
\end{tabular}


Table 3

Correlations for key variables

\begin{tabular}{|c|c|c|c|c|c|c|c|c|c|c|c|c|c|c|c|c|c|}
\hline Variable & 2 & 3 & 4 & 5 & 6 & 7 & 8 & 9 & 10 & 11 & 12 & 13 & 14 & 15 & 16 & 17 & 18 \\
\hline 1. Age $(\mathrm{T})$ & .14 & .56 & -.45 & $.22 *$ & .07 & $-.28 * *$ & -.14 & .02 & .19 & -.19 & .02 & .03 & $-.42 * * *$ & $.36 * * *$ & -.04 & .19 & .15 \\
\hline 2. Gender $(\mathrm{T})$ & & $.25^{* *}$ & .18 & -.06 & .10 & .03 & $.36 * * *$ & .09 & -.02 & $.24 *$ & -.06 & -.04 & -.19 & -.04 & -.12 & .04 & .06 \\
\hline 3. Restrained Eating ( $\mathrm{T}$ ) & & & .18 & .13 & .19 & .05 & $.31^{* *}$ & $.35 * * *$ & .06 & $.30 * *$ & .005 & .05 & -.001 & .08 & .10 & .07 & $-.24 *$ \\
\hline 4. Emotional Eating (T) & & & & $.44 * * *$ & $.91 * * *$ & -.10 & .13 & -.10 & .07 & .17 & -.15 & -.17 & -.02 & -.11 & .04 & $-.30 * *$ & -.10 \\
\hline 5. External Eating (T) & & & & & $.78 * * *$ & $-.32 * *$ & -.11 & -.07 & .16 & -.15 & -.03 & -.05 & $-.21^{*}$ & .10 & .10 & -.05 & -.04 \\
\hline 6. Overeating $(\mathrm{T})$ & & & & & & $-.22 *$ & .04 & .04 & .13 & .05 & -.12 & -.11 & -.11 & -.03 & .07 & $-.24 *$ & -.09 \\
\hline 7. Decides $(\mathrm{T})$ & & & & & & & $.26^{* *}$ & .12 & .06 & $.25^{*}$ & .10 & .18 & $.49 * * *$ & $.32 * *$ & .05 & .08 & -.02 \\
\hline 8. Harmful (T) & & & & & & & & .09 & -.09 & $.86^{* *}$ & .01 & .005 & .01 & -.08 & -.15 & -.11 & -.05 \\
\hline 9. Body Image Score (T) & & & & & & & & & -.05 & .11 & -.04 & .08 & -.002 & -.10 & $.22 *$ & -.03 & -.12 \\
\hline 10. Nutrition Score $(\mathrm{T})$ & & & & & & & & & & -.11 & .08 & .02 & .02 & .12 & -.02 & $.21^{*}$ & .11 \\
\hline 11. Harmfulness Revised (T) & & & & & & & & & & & .005 & .03 & .11 & -.11 & -.11 & -.13 & -.08 \\
\hline 12. Harmfulness $(\mathrm{P})$ & & & & & & & & & & & & $.92 * * *$ & $.20^{*}$ & -.06 & .01 & .17 & -.05 \\
\hline 13. Harmfulness Revised (P) & & & & & & & & & & & & & $.33 * *$ & -.02 & .03 & -.19 & -.09 \\
\hline 14. Decision Making $(\mathrm{P})$ & & & & & & & & & & & & & & -.17 & .17 & $-.20^{*}$ & .04 \\
\hline 15. Age (P) & & & & & & & & & & & & & & & .16 & .12 & -.05 \\
\hline 16. Employment (P) & & & & & & & & & & & & & & & & -.15 & $-.27 * *$ \\
\hline 17. Income (P) & & & & & & & & & & & & & & & & & .16 \\
\hline 18. Education $(\mathrm{P})$ & & & & & & & & & & & & & & & & & \\
\hline
\end{tabular}

Note. T denotes adolescent measures; $\mathrm{P}$ denotes female caregiver measures; $*=p<.05 ; * *=p<.01 ; * * *=p<.001$. 
Table 4

Means and standard errors for female caregivers' and adolescents' ratings of the harmfulness of food/eating behaviors

$$
M(S E)
$$

\section{Rater}

-Female Caregivers

-Adolescents

Age

-Young adolescents

-Older adolescents $3.08(.07)$

Note. No significant differences resulted; Estimated marginal means. 
Table 5

Means and standard errors for female caregivers' and adolescents' ratings of decision-making about food/eating behavior

$M(S E)$

Rater: $F(1,200)=24.92, p<.001, \eta_{\mathrm{p}}^{2}=.11$

-Female Caregivers

-Adolescents

$2.09(.07)$

Age: $F(1,200)=31.80, p<.001, \eta_{\mathrm{p}}{ }^{2}=.14$

-Young adolescents

-Older adolescents $2.06(.07)$

Note. Estimated marginal means. 
Table 6

Regression table for the association between adolescents' domain beliefs about food/eating behavior and over-eating behavior

$\mathrm{R}^{2^{*}} \quad \mathrm{R}^{2}$ F Change Beta

Step 1 .001 1.07

Gender

SES

Step 2

$-.01$

.70

Nutrition Knowledge

BID

Age

$-.01$

Step 3

.03

2.97

Decision-making $-.25 *$

Harmfulness

.10

Note. * Adj $\mathrm{R}^{2}=$ adjusted $R$; Beta's are from the final step of the regression; Non-significant 2way interactions from the final model were excluded from the table; ${ }^{*} p<.05 ; * * p<.01 ; * * p$ $<.001 ; \mathrm{SES}=$ socio-economic status (female caregivers' self-reported education level); BID = body image dissatisfaction. 
Table 7

Regression table for the association between adolescents' domain beliefs and food/eating behavior and under-eating behavior
$\mathrm{R}^{2^{*}}$
$\mathrm{R}^{2}$ F Change
Beta

Step 1

.11

$6.91 * *$

Gender

$.18^{+}$

SES

$-.22 *$

Step 2

.19

$4.57 * *$

Nutrition Knowledge

BID

Age

Step 3

.23

$3.12^{+}$

Decision-making

$-.02$

Harmfulness

$.23 *$

Note. * Adj $\mathrm{R}^{2}=$ adjusted $R$; Beta's are from the final step of the regression; Non-significant 2way interactions from the final model were excluded from the table; $* p<.05 ; * * p<.01 ; * * * p$ $<.001 ;{ }^{+} p=.05-.10 ; \mathrm{SES}=$ socio-economic status (female caregivers' self-reported education level); BID = body image dissatisfaction. 
Table 8

Regression table for the association between the discrepancy of female caregivers' and adolescents' domain judgments about food/eating behavior and adolescent over-eating behavior

\begin{tabular}{lccc}
\hline & $\mathrm{R}^{2^{*}}$ & $\mathrm{R}^{2}$ F Change & Beta \\
\hline Step 1 & .001 & 1.07 & \\
Gender & & & .16 \\
SES & & -.12
\end{tabular}

$\begin{array}{lll}\text { Step } 2 & -.01 & .70\end{array}$

Nutrition Knowledge $\quad .10$

$\begin{array}{ll}\text { BID } & .02\end{array}$

$\begin{array}{ll}\text { Age } & .07\end{array}$

$\begin{array}{lll}\text { Step } 3 & .02 & 2.36\end{array}$

Discrepancy decision-making $\quad .13$

Discrepancy harmfulness $\quad-.13$

$\begin{array}{lll}\text { Step } 4 & .11 & 5.77 * *\end{array}$

Discrepancy decides X Age $\quad-.25^{*}$

Discrepancy harm X BID $\quad .25^{*}$

Note. ${ }^{*}$ Adj $\mathrm{R}^{2}=$ adjusted $R$; Beta's are from the final step of the regression; Non-significant 2way interactions from the final model were excluded from the table; ${ }^{*} p<.05 ; * * p<.01 ; * * * p$ $<.001 ; \mathrm{SES}=$ socio-economic status (female caregivers' self-reported education level); $\mathrm{BID}=$ body image dissatisfaction; Discrepancy scores = female caregivers' ratings - adolescents' ratings. 
Table 9

Regression table for the association between the discrepancy of female caregivers' and adolescents' domain judgments about food/eating behavior and adolescent under-eating behavior

$\mathrm{R}^{2^{*}} \quad \mathrm{R}^{2}$ F Change $\quad$ Beta

$\begin{array}{lll}\text { Step } 1 & .11 & 6.91^{* *}\end{array}$

Gender

$.22 *$

SES

Step 2

.19

$4.57 * *$

Nutrition Knowledge

BID

Age

Step 3

Discrepancy decision-making

Discrepancy harmfulness

Note. * Adj $\mathrm{R}^{2}=$ adjusted $R$; Beta's are from the final step of the regression; Non-significant 2way interactions from the final model were excluded from the table; ${ }^{*} p<.05 ;{ }^{*} p<.01 ; * * * p$ $<.001 ;{ }^{+} p=.05-.10 ; \mathrm{SES}=$ socio-economic status (female caregivers' self-reported education level); BID = body image dissatisfaction; Discrepancy scores $=$ female caregivers' ratings adolescents' ratings. 


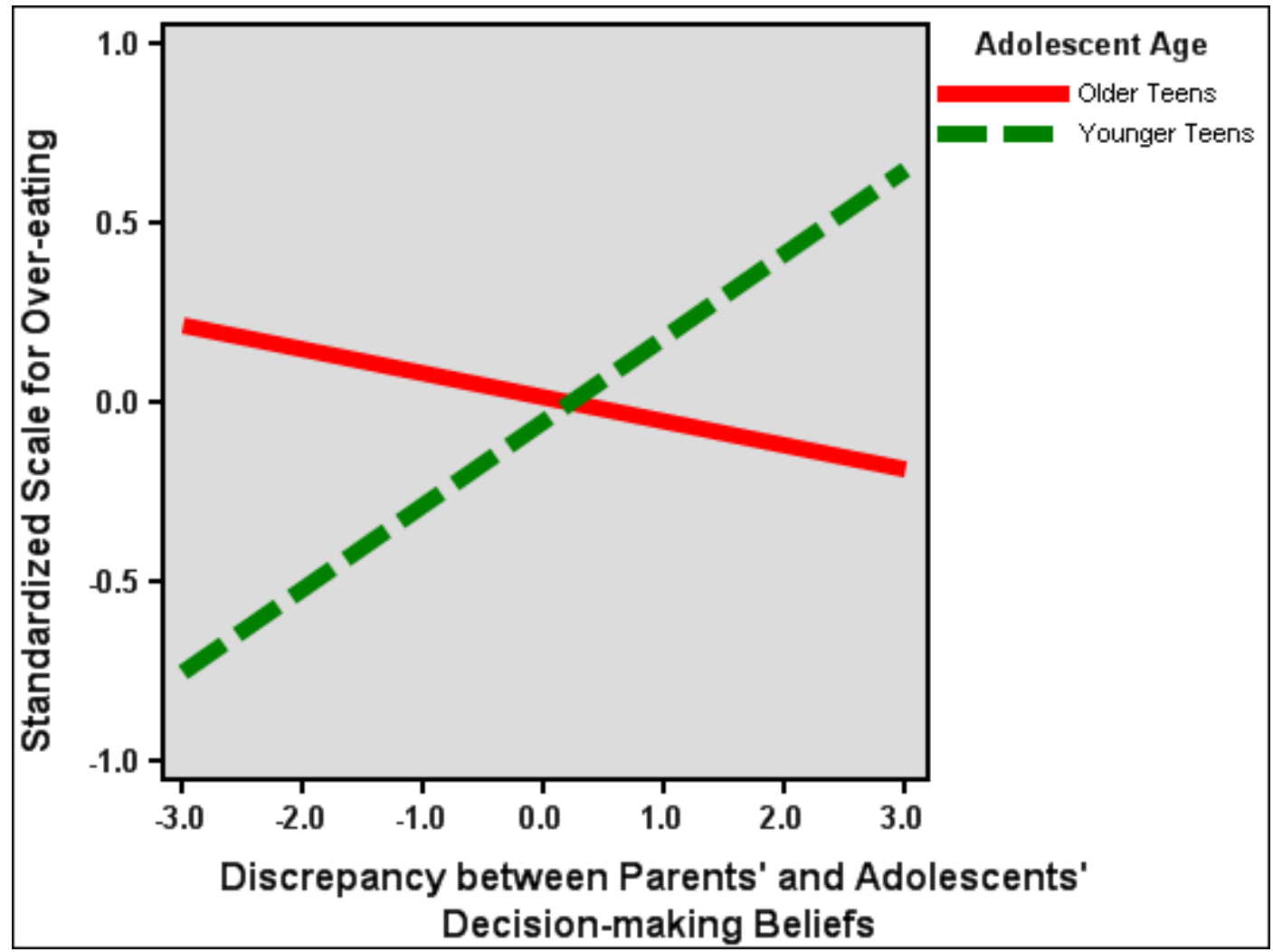

Figure 1. Discrepancy between female caregivers' and adolescents' decision-making beliefs by adolescent age interaction graph. Discrepancy decision-making = female caregivers' decisionmaking beliefs - adolescents' decision-making beliefs. 


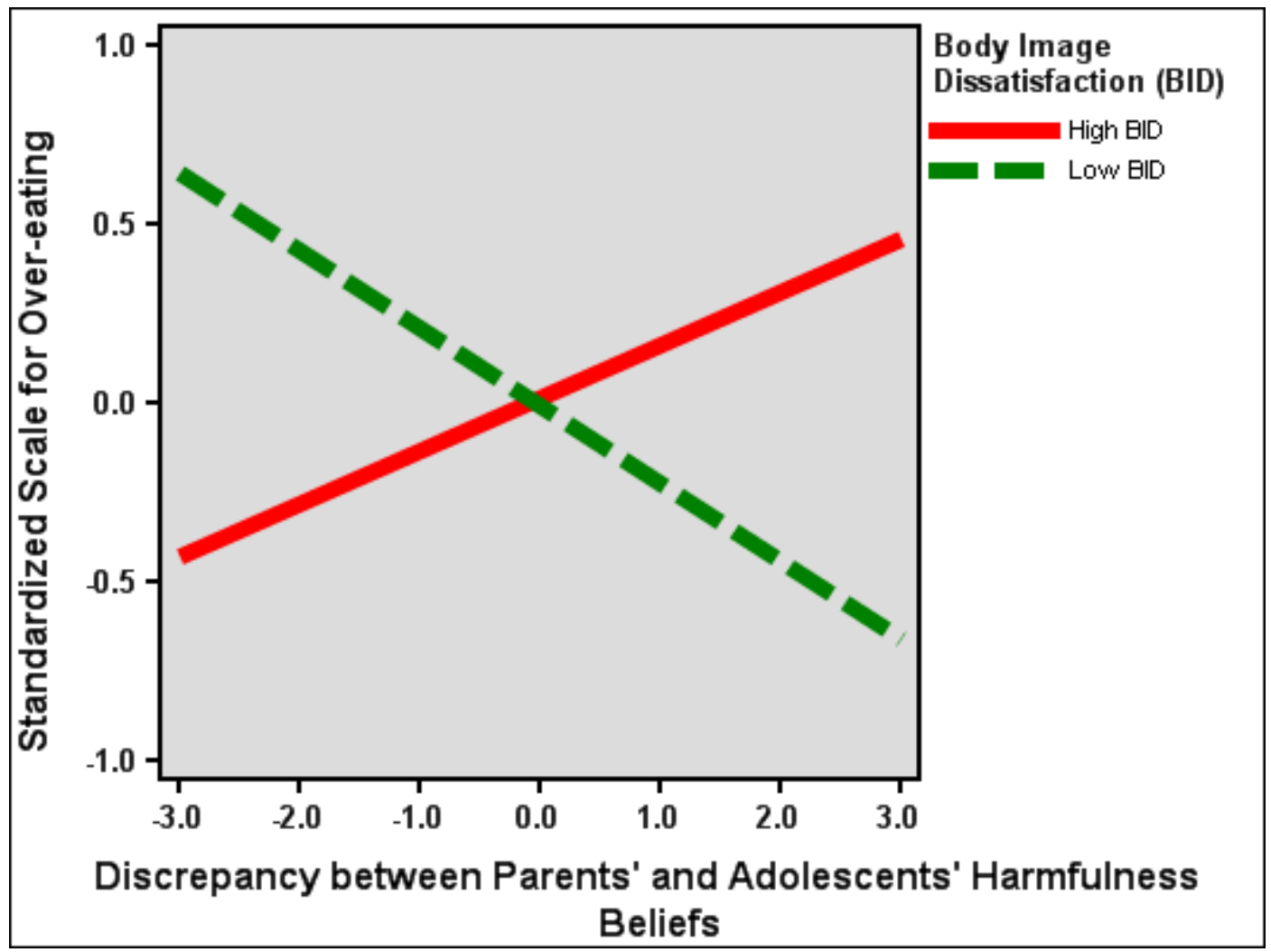

Figure 2. Discrepancy between female caregivers' and adolescents' harmfulness judgments by adolescent body image dissatisfaction level interaction graph. Discrepancy harmfulness beliefs = female caregivers' harmfulness beliefs - adolescents' harmfulness beliefs. 


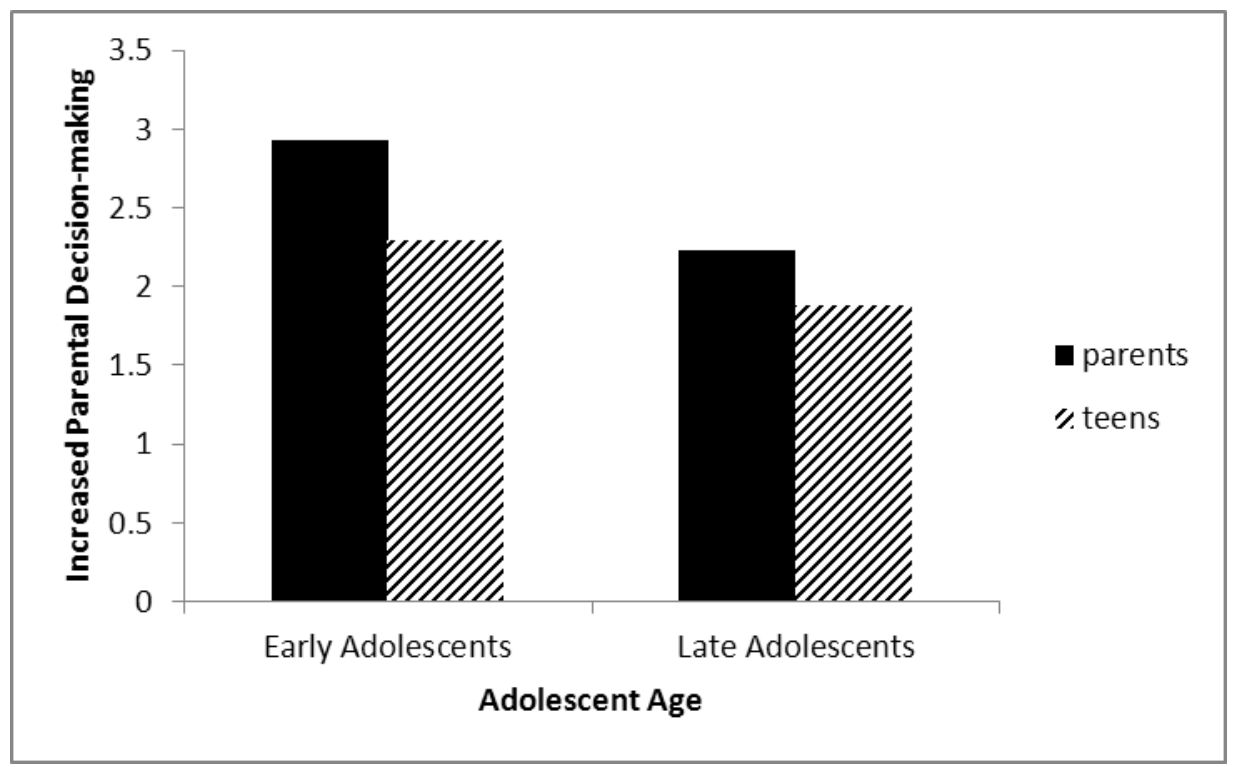

Figure 3. Differences in female caregivers' and adolescents' decision-making beliefs moderated by adolescent age. Non-significant interaction $F(1,200)=2.10, p=.15$. 


\section{Appendix A}

\section{Demographics - Adolescent}

1. What gender are you?

Male Female

2. How old are you? (years) What is your birthday? (Month/Day/Year)

3. What is your grade in school? $6^{\text {th }} \quad 7^{\text {th }} \quad 8^{\text {th }} 9^{\text {th }} \quad 10^{\text {th }} \quad 11^{\text {th }} \quad 12^{\text {th }}$

4. School grades (Please circle):

$\square$ Mostly A's

$\square$ Some A's some B's

Mostly B's

$\square$ Some B's some C's

$\square$ Mostly C's

$\square$ Some C's some D's

$\square$ Mostly D's or lower

5. What is your ethnicity (Please circle)?

African-American/Black

Asian-American/Pacific Islander

Caucasian/White $\neg$ Hispanic/Latino

$\square$ Native American

$\square$ Other (describe)

6. Who currently lives in your home (Circle all that apply)?

$\square$ mother (birth or adopted) $\square$ stepmother

$\square$ father (birth or adopted) $\quad \square$ stepfather

$\square$ brothers/sisters? (ages of siblings)

$\square$ other adults (who?)

7. What is the highest level of schooling your mother (or female guardian) completed?

Completed $8^{\text {th }}$ grade

Completed high school

Completed college

Graduate degree (doctor, lawyer, $\mathrm{PhD}$ )

Don't know or unsure

At what type of JOB does your MOTHER work?
8. What is the highest level of schooling your father (or male guardian) completed?

Completed $8^{\text {th }}$ grade

Completed high school

Completed college

$\checkmark$ Graduate degree (doctor, lawyer, $\mathrm{PhD}$ )

Don't know or unsure

At what type of JOB does your FATHER work? 
8. How much education would you like to get?

$\square$ I don't care if I finish high school

$\square$ I want to finish high school

$\square$ I want some college

I want to finish a four-year college

$\square$ I want more education after college, such as a graduate or professional degree (such as a law, medical, doctorate/Ph.D., business/M.B.A.)

9. What is your ideal future career?

10. Do you participate in the free or reduced lunch program?

No Yes

11. Have you ever been diagnosed with a reading disability?

No Yes

12. Do you currently receive tutoring for reading?

@No Yes

Please respond honestly and fully, don't forget your answers are confidential. Answer the following questions based on how you feel about yourself and food:

13. How tall are you? feet inches

14. How much do you weigh? Pounds

15. How do you think of yourself?

$\begin{array}{ll}8 & \text { Very underweight } \\ 8 & \text { Slightly underweight } \\ 8 & \text { About the right weight } \\ & \text { Slightly overweight } \\ & \text { Very overweight }\end{array}$

17. How healthy are you?

$\begin{array}{ccccc}1 & 2 & 3 & 4 & 5 \\ \text { Not Healthy } & & & & \text { Very Healthy }\end{array}$

16. Which of the following are you trying to do:

\begin{tabular}{|c|c|}
\hline & Lose weight \\
\hline & $\begin{array}{l}\text { Maintain my weight/stay the } \\
\text { same }\end{array}$ \\
\hline & Gain weight \\
\hline & $\begin{array}{l}\text { I am not trying to do anything } \\
\text { about my weight }\end{array}$ \\
\hline
\end{tabular}


Demographics - Parent

1. What gender are you?

Male Female

2. What is your relationship to the adolescent in the study?

Birth Mother Birth Father Grandparent $\quad$ Step-Mother

Step-Father Adoptive Mother Adoptive Father

Other relative (aunt, uncle, brother, sister, cousin, etc.)

Other relative (specify):

Other guardian (specify):

3. What is your present marital status?

$\square$ Married
$\square$ Divorced/Separated
$\square$ Widowed
$\square$ Single, never married
$\square$ Living with a romantic partner

4. For how long have you had your present marital status? years

5. How old are you? (years) What is your birthday? (Month/Day/Year)

6. What is your ethnicity (Please circle)?

African-American/Black

Asian-American/Pacific Islander

Caucasian/White
Hispanic/Latino

Native American

Other (describe)

7. What is the highest level of education you have completed?

$\square$ Completed $8^{\text {th }}$ grade

Completed high school

Completed college

$\square$ Business or Technical School

$\checkmark$ Graduate degree (doctor, lawyer, $\mathrm{PhD}$ )

8. Are you currently employed?

Yes, full-time $\quad$ Yes, part-time No 
9. Are you a student?

$$
\square \text { Yes, full-time } \quad \square \text { Yes, part-time } \quad \square \text { No }
$$

10. Which best describes your total yearly household income?

$$
\begin{aligned}
& \square \$ 11,999 \text { or less } \\
& \square \$ 12,000 \text { to } 24,999 \\
& \square \$ 25,000 \text { to } 49,999 \\
& \square \$ 50,000 \text { to } 74,999 \\
& \square \$ 75,000 \text { to } 99,999 \\
& \square \$ 100,000 \text { to } 149,999 \\
& \square \$ 150,000 \text { or above }
\end{aligned}
$$

11. Does your child participate in a free or reduced lunch program?

$$
\text { No Yes }
$$

12. How tall are you? ___ feet __ inches

13. How much do you weigh? ___ Pounds 
Appendix B

Figure Rating Scale

\section{Instructions:}

Please look at the following pictures. Choose the picture that best answers each question.
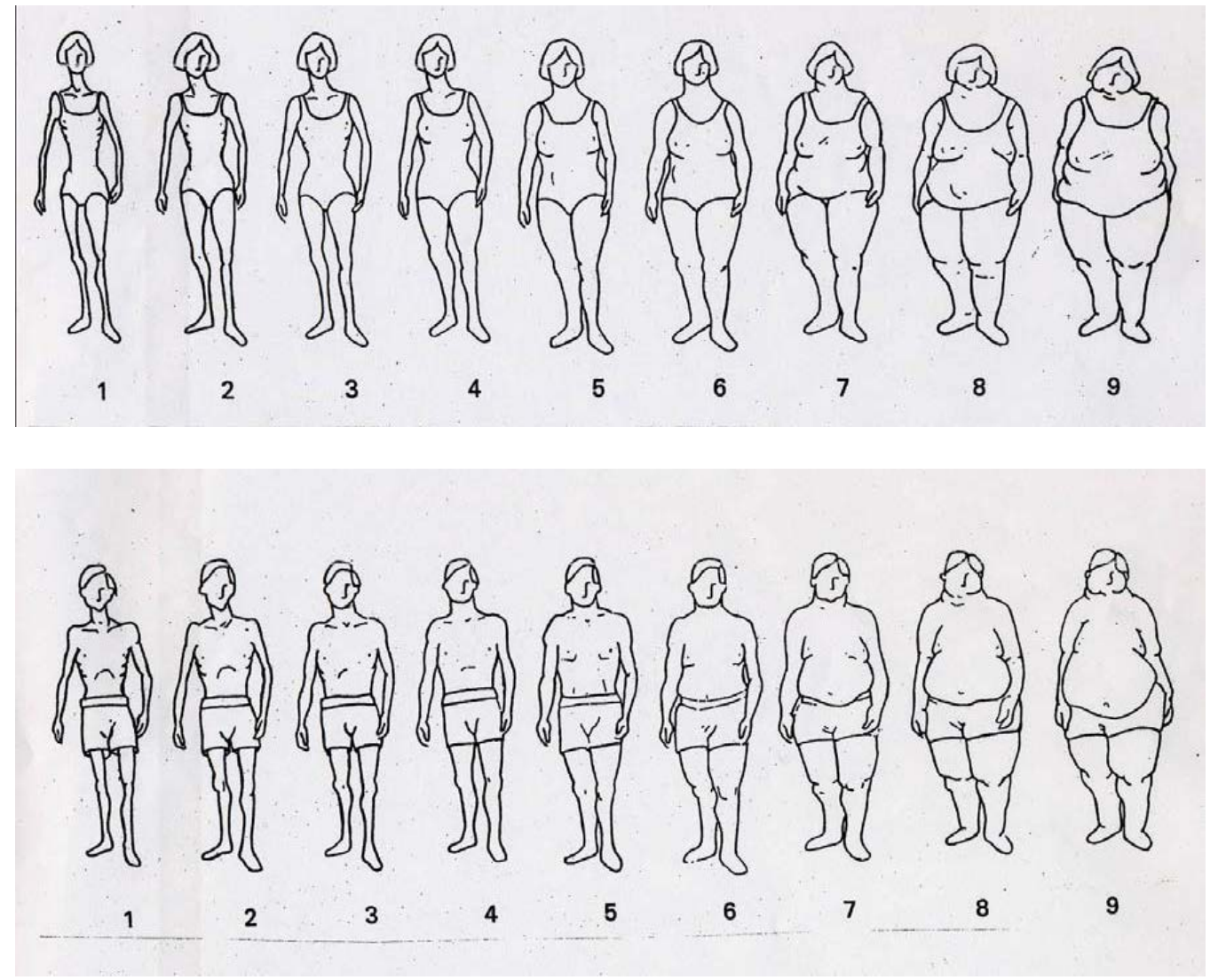

Which number shows how you currently look?

Which number shows how you wish you look? 
Appendix C

General Nutrition Knowledge Questionnaire for Adults

Please answer the following questions based on your food knowledge.

1. How many servings of fruit and vegetables a day do you think experts are advising people to eat? (One serving could be, for example, an apple or a handful of chopped carrots).*

\begin{tabular}{|c|c|c|c|c|}
\hline \multicolumn{2}{|l|}{$\begin{array}{l}\text { 2. Do you think experts put these in the starchy foods group? (pick one box } \\
\text { per food) }\end{array}$} & Yes & No & $\begin{array}{l}\text { Not } \\
\text { Sure }\end{array}$ \\
\hline \multicolumn{2}{|l|}{ Cheese } & $\mathrm{Y}$ & $\mathrm{N}$ & NS \\
\hline \multicolumn{2}{|l|}{ Pasta } & $\mathrm{Y}$ & $\mathrm{N}$ & NS \\
\hline \multicolumn{2}{|l|}{ Butter } & $\mathrm{Y}$ & $\mathrm{N}$ & NS \\
\hline \multicolumn{2}{|l|}{ Nuts } & $\mathrm{Y}$ & $\mathrm{N}$ & NS \\
\hline \multicolumn{2}{|l|}{ Rice } & $\mathrm{Y}$ & $\mathrm{N}$ & NS \\
\hline \multicolumn{2}{|l|}{ Oatmeal } & $\mathrm{Y}$ & $\mathrm{N}$ & NS \\
\hline $\begin{array}{l}\text { 3. Do you think these are high or low in fat? (pick one box per } \\
\text { food) }\end{array}$ & High & Low & $\begin{array}{l}\text { Not } \\
\text { Sure }\end{array}$ & \\
\hline Pasta (without sauce) & $\mathrm{H}$ & $\overline{\mathrm{L}}$ & $\mathrm{NS}$ & \\
\hline Low fat spread & $\mathrm{H}$ & $\mathrm{L}$ & NS & \\
\hline Baked beans & $\mathrm{H}$ & $\mathrm{L}$ & NS & \\
\hline Luncheon meat & $\mathrm{H}$ & $\mathrm{L}$ & NS & \\
\hline Honey & $\mathrm{H}$ & $\mathrm{L}$ & NS & \\
\hline Nuts & $\mathrm{H}$ & $\mathrm{L}$ & NS & \\
\hline Bread & $\mathrm{H}$ & $\mathrm{L}$ & NS & \\
\hline Cheese & $\mathrm{H}$ & $\mathrm{L}$ & NS & \\
\hline Polyunsaturated margarine & $\mathrm{H}$ & $\mathrm{L}$ & NS & \\
\hline $\begin{array}{l}\text { 4. Do you think these are high or low in salt? (pick one box per } \\
\text { food) }\end{array}$ & High & Low & $\begin{array}{l}\text { Not } \\
\text { Sure }\end{array}$ & \\
\hline Sausages & $\mathrm{H}$ & $\mathrm{L}$ & $\mathrm{NS}$ & \\
\hline Pasta & $\mathrm{H}$ & $\mathrm{L}$ & $\mathrm{NS}$ & \\
\hline Anchovies & $\mathrm{H}$ & $\mathrm{L}$ & NS & \\
\hline Red Meat & $\mathrm{H}$ & $\mathrm{L}$ & NS & \\
\hline Frozen Vegetables & $\mathrm{H}$ & $\mathrm{L}$ & $\mathrm{NS}$ & \\
\hline Cheese & $\mathrm{H}$ & $\mathrm{L}$ & NS & \\
\hline $\begin{array}{l}\text { 5. Do you think these are high or low in protein? (pick one box per } \\
\text { food) }\end{array}$ & High & Low & $\begin{array}{l}\text { Not } \\
\text { Sure }\end{array}$ & \\
\hline Chicken & $\mathrm{H}$ & $\mathrm{L}$ & $\mathrm{NS}$ & \\
\hline Cheese & $\mathrm{H}$ & $\mathrm{L}$ & NS & \\
\hline Fruit & $\mathrm{H}$ & $\mathrm{L}$ & NS & \\
\hline Baked Beans & $\mathrm{H}$ & $\mathrm{L}$ & NS & \\
\hline Butter & $\mathrm{H}$ & $\mathrm{L}$ & NS & \\
\hline Cream & $\mathrm{H}$ & $\mathrm{L}$ & NS & \\
\hline
\end{tabular}




\begin{tabular}{|l|c|c|c|}
\hline $\begin{array}{l}\text { 6. Do you think these are high or low in fiber? (pick one box per } \\
\text { food) }\end{array}$ & High & Low & $\begin{array}{c}\text { Not } \\
\text { Sure }\end{array}$ \\
\hline Cornflakes & H & L & NS \\
Bananas & H & L & NS \\
Eggs & H & L & NS \\
Red Meat & H & L & NS \\
Broccoli & H & L & NS \\
Nuts & H & L & NS \\
Fish & H & L & NS \\
Baked Potatoes with skins & H & L & NS \\
Chicken & H & L & NS \\
Baked Beans & H & L & NS \\
\hline
\end{tabular}

Note. * Item dropped from the Nutrition Knowledge Questionnaire. 
Appendix D

Dutch Eating Behavior Questionnaire

\begin{tabular}{|c|c|c|c|c|c|}
\hline Eating behavior questions & Never & Seldom & Sometimes & Often & $\begin{array}{l}\text { Very } \\
\text { often }\end{array}$ \\
\hline $\begin{array}{l}\text { 1. When you have put on weight, do you eat } \\
\text { less than you usually do? }\end{array}$ & 1 & 2 & 3 & 4 & 5 \\
\hline $\begin{array}{l}\text { 2. Do you try to eat less at mealtimes than } \\
\text { you would like to eat? }\end{array}$ & 1 & 2 & 3 & 4 & 5 \\
\hline $\begin{array}{l}\text { 3. How often do you refuse food or drinks } \\
\text { offered because you are concerned about } \\
\text { your weight? }\end{array}$ & 1 & 2 & 3 & 4 & 5 \\
\hline 4. Do you watch exactly what you eat? & 1 & 2 & 3 & 4 & 5 \\
\hline $\begin{array}{l}\text { 5. Do you deliberately eat foods that are } \\
\text { slimming? }\end{array}$ & 1 & 2 & 3 & 4 & 5 \\
\hline $\begin{array}{l}\text { 6. When you have eaten too much, do you eat } \\
\text { less than usual the following day? }\end{array}$ & 1 & 2 & 3 & 4 & 5 \\
\hline $\begin{array}{l}\text { 7. Do you deliberately eat less in order not to } \\
\text { become heavier? }\end{array}$ & 1 & 2 & 3 & 4 & 5 \\
\hline $\begin{array}{l}\text { 8. How often do you try not to eat between } \\
\text { meals because you are watching your } \\
\text { weight? }\end{array}$ & 1 & 2 & 3 & 4 & 5 \\
\hline $\begin{array}{l}\text { 9. How often in the evenings do you try not } \\
\text { to eat because you are watching your } \\
\text { weight? }\end{array}$ & 1 & 2 & 3 & 4 & 5 \\
\hline $\begin{array}{l}\text { 10. Do you take into account your weight with } \\
\text { what you eat? }\end{array}$ & 1 & 2 & 3 & 4 & 5 \\
\hline $\begin{array}{l}\text { 11. Do you have the desire to eat when you are } \\
\text { irritated? }\end{array}$ & 1 & 2 & 3 & 4 & 5 \\
\hline $\begin{array}{l}\text { 12. Do you have a desire to eat when you have } \\
\text { nothing to do? }\end{array}$ & 1 & 2 & 3 & 4 & 5 \\
\hline
\end{tabular}




\begin{tabular}{|c|c|c|c|c|c|}
\hline $\begin{array}{l}\text { 13. Do you have a desire to eat when you are } \\
\text { depressed or discouraged? }\end{array}$ & 1 & 2 & 3 & 4 & 5 \\
\hline $\begin{array}{l}\text { 14. Do you have a desire to eat when you are } \\
\text { feeling lonely? }\end{array}$ & 1 & 2 & 3 & 4 & 5 \\
\hline $\begin{array}{l}\text { 15. Do you have a desire to eat when } \\
\text { somebody lets you down? }\end{array}$ & 1 & 2 & 3 & 4 & 5 \\
\hline $\begin{array}{l}\text { 16. Do you have a desire to eat when you are } \\
\text { angry or upset? }\end{array}$ & 1 & 2 & 3 & 4 & 5 \\
\hline $\begin{array}{l}\text { 17. Do you have a desire to eat when you are } \\
\text { expecting something unpleasant to } \\
\text { happen? }\end{array}$ & 1 & 2 & 3 & 4 & 5 \\
\hline $\begin{array}{l}\text { 18. Do you get the desire to eat when you are } \\
\text { anxious, worried or tense? }\end{array}$ & 1 & 2 & 3 & 4 & 5 \\
\hline $\begin{array}{l}\text { 19. Do you have a desire to eat when things } \\
\text { are going against you or when things have } \\
\text { gone wrong? }\end{array}$ & 1 & 2 & 3 & 4 & 5 \\
\hline $\begin{array}{l}\text { 20. Do you have a desire to eat when you are } \\
\text { frightened? }\end{array}$ & 1 & 2 & 3 & 4 & 5 \\
\hline $\begin{array}{l}\text { 21. Do you have a desire to eat when you are } \\
\text { disappointed? }\end{array}$ & 1 & 2 & 3 & 4 & 5 \\
\hline $\begin{array}{l}\text { 22. Do you have a desire to eat when you are } \\
\text { emotionally upset? }\end{array}$ & 1 & 2 & 3 & 4 & 5 \\
\hline $\begin{array}{l}\text { 23. Do you have a desire to eat when you are } \\
\text { bored or restless? }\end{array}$ & 1 & 2 & 3 & 4 & 5 \\
\hline $\begin{array}{l}\text { 24. If food tastes good to you, do you eat more } \\
\text { than usual? }\end{array}$ & 1 & 2 & 3 & 4 & 5 \\
\hline $\begin{array}{l}\text { 25. If food smells and looks good, do you eat } \\
\text { more than usual? }\end{array}$ & 1 & 2 & 3 & 4 & 5 \\
\hline $\begin{array}{l}\text { 26. If you see or smell something delicious, do } \\
\text { you have a desire to eat it? }\end{array}$ & 1 & 2 & 3 & 4 & 5 \\
\hline
\end{tabular}




\begin{tabular}{|l|lllll|}
\hline $\begin{array}{l}\text { 27. If you have something delicious to eat, do } \\
\text { you eat it right away? }\end{array}$ & 1 & 2 & 3 & 4 & 5 \\
\hline $\begin{array}{l}\text { 28. If you walk past a convenience store or fast } \\
\text { food restaurant do you have the desire to } \\
\text { buy something delicious? }\end{array}$ & 1 & 2 & 3 & 4 & 5 \\
\hline $\begin{array}{l}\text { 29. If you walk past a snack bar or a café, do } \\
\text { you have the desire to buy something } \\
\text { delicious? }\end{array}$ & 1 & 2 & 3 & 4 & 5 \\
\hline $\begin{array}{l}\text { 30. If you see others eating, do you have the } \\
\text { desire to eat? }\end{array}$ & 1 & 2 & 3 & 4 & 5 \\
\hline $\begin{array}{l}\text { 31. Can you resist eating delicious foods? } \\
\text { 32. Do you eat more than usual, when you see } \\
\text { others eating? }\end{array}$ & 1 & 2 & 3 & 4 & 5 \\
33. When preparing a meal are you inclined to \\
eat something?
\end{tabular}

Note. Items 1-10 = Under-eating behavior (Restrained eating subscale); Items 11-33 = Overeating behavior (Emotional and External eating subscales). 
Appendix E

\section{Parental Restrictive Control Questionnaire - Adolescent}

Now, circle the number that best decides who in your family makes most of the decisions about each of the topics below, using the following scale:

1. I decide this without discussing it with my parent(s) or guardian(s).

2. I make the final decision after discussing it with my parent(s) or guardian(s).

3. My parent(s) and I make the decision together.

4. My parent(s) make the final decision after discussing it with me.

5. My parent(s) decide this without discussing it with me.

\begin{tabular}{|c|c|c|c|c|c|}
\hline & $\begin{array}{l}\text { Child } \\
\text { decides }\end{array}$ & $\begin{array}{l}\text { Mainly } \\
\text { child }\end{array}$ & $\begin{array}{l}\text { Decide } \\
\text { together }\end{array}$ & $\begin{array}{l}\text { Mainly } \\
\text { parent }\end{array}$ & $\begin{array}{l}\text { Parent } \\
\text { decides }\end{array}$ \\
\hline 1. What I eat while at home & 1 & 2 & 3 & 4 & 5 \\
\hline 2. What I eat while away from home & 1 & 2 & 3 & 4 & 5 \\
\hline $\begin{array}{l}\text { 3. What foods are bought for meals at } \\
\text { home }\end{array}$ & 1 & 2 & 3 & 4 & 5 \\
\hline 4. If I eat "junk food" & 1 & 2 & 3 & 4 & 5 \\
\hline $\begin{array}{l}\text { 5. Whether I am dieting or trying to lose } \\
\text { weight (stop eating when you are } \\
\text { hungry) }\end{array}$ & 1 & 2 & 3 & 4 & 5 \\
\hline 5. If I eat snacks between meals & 1 & 2 & 3 & 4 & 5 \\
\hline $\begin{array}{l}\text { 6. Whether I continue to eat after I am } \\
\text { full }\end{array}$ & 1 & 2 & 3 & 4 & 5 \\
\hline
\end{tabular}

Parental Restrictive Control Questionnaire - Parent

Now, circle the number that best describes within your family who makes most of the decisions about each of the topics below using the following scale:

1. Child decides without discussing it with me (parent).

2. Child makes final decision after discussing it with me (parent).

3. My child and I make the decision together.

4. I make the final decision after discussing it with my child.

5. I decide this without discussing it with my child.

\begin{tabular}{|l|c|c|c|c|c|}
\hline & $\begin{array}{c}\text { Child } \\
\text { decides }\end{array}$ & $\begin{array}{c}\text { Mainly } \\
\text { child }\end{array}$ & $\begin{array}{c}\text { Decide } \\
\text { together }\end{array}$ & $\begin{array}{c}\text { Mainly } \\
\text { parent }\end{array}$ & $\begin{array}{c}\text { Parent } \\
\text { decides }\end{array}$ \\
\hline $\begin{array}{l}\text { 1. What your child can eat in between } \\
\text { meals? }\end{array}$ & 1 & 2 & 3 & 4 & 5 \\
$\begin{array}{l}\text { 2. Whether your child can lose weight or } \\
\text { go on a diet? }\end{array}$ & 1 & 2 & 3 & 4 & 5 \\
\hline $\begin{array}{l}\text { 3. Whether your child can eat "junk } \\
\text { food"? }\end{array}$ & 1 & 2 & 3 & 4 & 5 \\
\hline 4. How much my child eats? & 1 & 2 & 3 & 4 & 5 \\
\hline
\end{tabular}


Appendix F

Harmfulness Rating Scale - Adolescent

\begin{tabular}{|l|c|c|c|c|c|}
\hline How harmful are the following activities? & $\begin{array}{c}\text { Not } \\
\text { harmful } \\
\text { at all } \\
1\end{array}$ & 2 & 3 & 4 & $\begin{array}{c}\text { Extremely } \\
\text { harmful } \\
5\end{array}$ \\
\hline 1. Continuing to eat after you are full? & 1 & 2 & 3 & 4 & 5 \\
2. Eating "junk food" & 1 & 2 & 3 & 4 & 5 \\
3. Eating snacks between meals & 1 & 2 & 3 & 4 & 5 \\
$\begin{array}{l}\text { 4. Dieting or trying to lose weight (stop } \\
\text { eating when you are hungry)?* }\end{array}$ & 1 & 2 & 3 & 4 & 5 \\
\hline
\end{tabular}

Harmfulness - Parent

\begin{tabular}{|c|c|c|c|c|c|}
\hline $\begin{array}{l}\text { How harmful are the following } \\
\text { activities? }\end{array}$ & $\begin{array}{l}\text { Not at all } \\
\text { harmful } \\
1\end{array}$ & 2 & 3 & 4 & $\begin{array}{l}\text { Extremely } \\
\text { harmful } \\
5\end{array}$ \\
\hline $\begin{array}{l}\text { 1. If teens continue to eat after they } \\
\text { are full? }\end{array}$ & 1 & 2 & 3 & 4 & 5 \\
\hline 2. If teens eat "junk food" & 1 & 2 & 3 & 4 & 5 \\
\hline 3. If teens eat snacks between meals & 1 & 2 & 3 & 4 & 5 \\
\hline $\begin{array}{l}\text { 4. If teens are dieting or trying to } \\
\text { lose weight (stop eating when they } \\
\text { are hungry)?* }\end{array}$ & 1 & 2 & 3 & 4 & 5 \\
\hline
\end{tabular}

Note. * Item removed from the parent and adolescent Harmfulness Revised Subscales. 
Running Head: ADOLESCENT AUTONOMY AND EATING 